\title{
Computational Fluid Dynamics (CFD) Modelling to Estimate Fluvial Bank Erosion-A Case Study
}

\author{
Emmanouil Spyropoulos ${ }^{1}$, Stephen E. Darby ${ }^{2}$ \\ ${ }^{1}$ Saudi Aramco, Geotechnical Engineer, Dhahran, Kingdom of Saudi Arabia \\ ${ }^{2}$ School of Geography and Environmental Sciences, University of Southampton, Southampton, United Kingdom \\ Email: emmanouil.spyropoulos@aramco.com, S.E.Darby@soton.ac.uk
}

How to cite this paper: Spyropoulos, E., \& Darby, S. E. (2020). Computational Fluid Dynamics (CFD) Modelling to Estimate Fluvial Bank Erosion-A Case Study. Journal of Geoscience and Environment Protection, 8, 17-43.

https://doi.org/10.4236/gep.2020.87002

Received: June 10, 2020

Accepted: July 12, 2020

Published: July 15, 2020

Copyright $\odot 2020$ by author(s) and Scientific Research Publishing Inc. This work is licensed under the Creative Commons Attribution International License (CC BY 4.0).

http://creativecommons.org/licenses/by/4.0/

\begin{abstract}
River bank erosion models are an important prerequisite for understanding the development of river meanders and for estimating likely land-loss and potential danger to floodplain infrastructure. Although bank erosion models have been developed that consider large-scale mass failure, the contribution of fluvial erosion (the process of particle-by-particle erosion due to the shearing action of the river flow) to bank retreat has not received as much consideration. In principle, such fluvial bank erosion rates can be quantified using excess shear stress formulations, but in practice, it has proven difficult to estimate the parameters involved. In this study, a series of three-dimensional Computational Fluid Dynamics (CFD) simulations for a meander loop on the River Asker (200 m long) at Bridport in southern England were undertaken to elucidate the overall flow structures and in particular to provide estimates of the applied fluid shear stress exerted on the riverbanks. The CFD models, which simulated relatively low and relatively high flow conditions, were established using Fluent 6.2 software. The modelling outcomes show that the key qualitative features of the flow endure even as flow discharge varies. At bank full, the degrees of velocity and simulated shear stresses within the inner bank separation zones are shown to be higher than those observed under low flow conditions, and that these elevated shear stresses may be sufficient to result in the removal of accumulated sediments into the main downstream flow.
\end{abstract}

\section{Keywords}

Computational Fluid Dynamics, CFD, Bank Erosion, Fluvial

\section{Introduction}

Bank erosion is a major natural hazard, causing numerous complications due to 
the retreat of land, which can damage infrastructure located alongside water bodies and contribute to the buildup of eroded sediments in downstream stretches (Lawler et al., 1997; Rinaldi \& Casagli, 1999; Hackney et al., 2020). Therefore, it is vital to comprehend the mechanisms of stream bank erosion in order to understand how to mitigate the detrimental effects caused by these issues.

Bank erosion is characterized by a blend of large-scale, periodic, mass failures that occur in parallel to the smaller-scale, but gradual, removal of bank materials by the flow shearing action.

While progress has been made concerning understanding the processes governing large-scale mass failures (Osman \& Thorne, 1988; Rinaldi \& Casagli, 1999; Casagli et al., 1999; Simon \& Collison, 2002), not as much research has been dedicated to the fluvial entrainment of river bank materials (Darby et al., 2010, 2013). This is an important gap, because fluvial entrainment can itself frequently cause mass failure.

For non-cohesive sediments, fluvial erosion can be established by consideration of sediment transport dynamics in the near-bank zone (ASCE Task Committee, 1998b). However, fluvial erosion of fine-grained, cohesive, bank sediments is much more complex compared to the case of non-cohesive materials. Within cohesive deposits comprised of noteworthy quantities of silt and clay, the governing forces resisting fluvial entrainment are inter-particle forces owing to cohesion rather than the submerged weight of the particles.

Excess shear stress models are widely accepted as representing fluvial erosion rates of cohesive materials, through the following equation (Partheniades, 1965):

$$
E=k\left(\tau-\tau_{c}\right)
$$

where $E$ is the fluvial bank erosion rate, $\tau$ is the applied fluid shear stress, $\tau_{c}$ is the critical stress for entrainment of the bank material, and $k$ is an empirically derived erodibility parameter.

In this equation, the applied fluid shear stress must be in excess of the critical shear stress to initiate erosion. Previous work has shown that erosion rates increase rapidly once the threshold shear stress is exceeded (Partheniades, 1965). However, detailed evaluation of the validity of this excess shear stress model necessitates precise data for the applied fluid shear stresses, fluvial erosion rates, critical shear stresses, and the erodibility parameters of the bank materials, and these have all proved to be challenging to quantify (Midgley et al., 2012). This means that the validity of the form of Equation (1) remains unestablished.

The critical shear stress of the bank sediments can be estimated with some confidence through the use of jet-testing devices (Hanson \& Simon, 2001; Dapporto, 2001; Midgley et al., 2012). Hanson and Simon (2001) have also established that the bank erodibility parameter, $k$, is a co-variate of $\tau_{c}$ such that:

$$
k=0.2 \tau_{C}^{-0.5}
$$

As a result, the ability to predict fluvial erosion via Equation (1) is strongly 
linked to the ability to estimate the applied fluid shear stresses exerted on the banks, especially in hazardous floods that typically drive bank erosion. The examination and evaluation of applied shear stresses on riverbanks is, therefore, the major objective of this paper. Some previous studies, such as Kean and Smith (2006), Darby et al. (2010) and Hackney et al. (2015), Leyland et al. (2015) have developed analytical techniques to estimate these applied river bank shear stresses. However, these studies need to make assumptions in order to develop closeable solutions, in particular idealizing the representation of turbulence. This means that they may introduce simplifications that limit the broader transferability of their findings. To address this issue, here we present a series of fully three-dimensional Computational Fluid Dynamics (CFD) simulations for a meander loop on the River Asker (200 m long) at Bridport in southern England as a novel means of estimating the applied fluid shear stress exerted on riverbanks. Bank erodibility and deformation data related to competent flows were also derived through the use of erosion pins accompanied by high-resolution digital photogrammetry. The CFD models under specific steady peak flow environments were established using Fluent 6.2 (Fluent Inc., 2006) software. Full details of the methods employed and the associated results are now provided.

\section{Study Area}

The River Asker flows through Bridport in Dorset (United Kingdom), and at the study site the upstream drainage area is $49.1 \mathrm{~km}^{2}$. The study site is centered on the UK National Grid Reference SY 471,929. The River Asker site location is displayed in Figure 1.

This particular location was ideal for use in this study as river stage and discharge information are freely accessible from a gauging station located approximately 150 meters downstream. The entire extent of the considered reach is

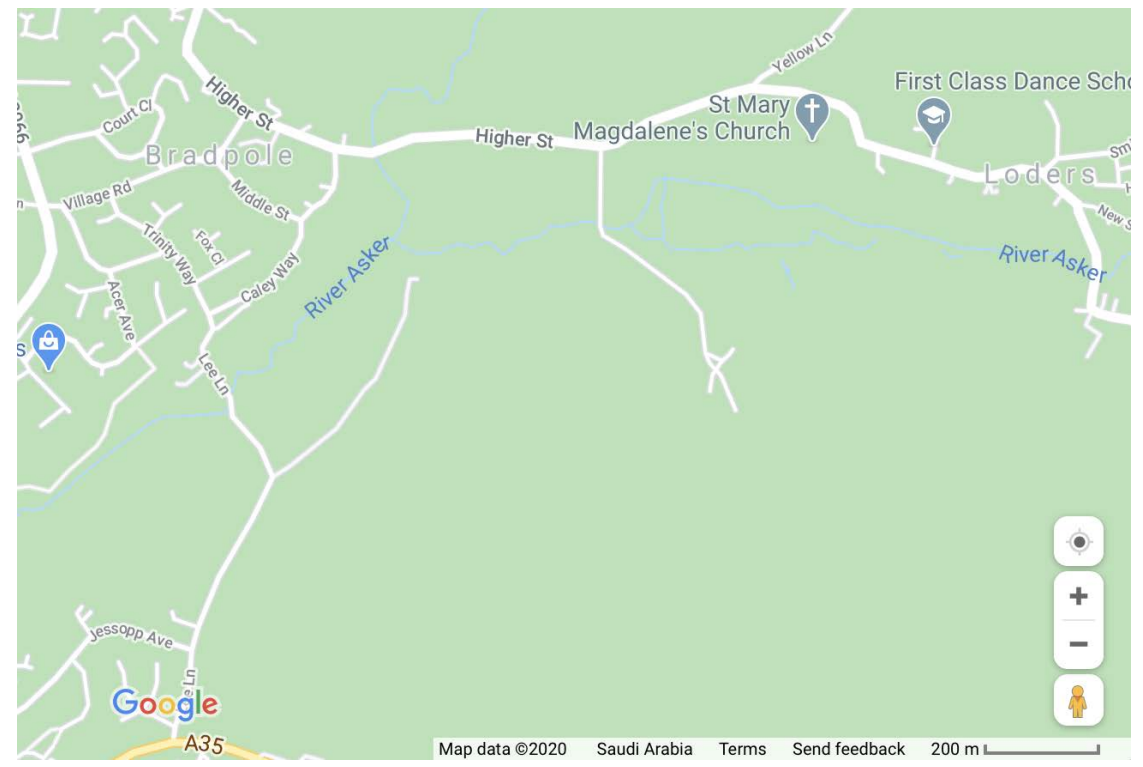

Figure 1. Location of the river asker site in Bridport, Dorset. 
roughly $200 \mathrm{~m}$, with an average gradient of 0.007 . The eroding bank has a typical height of about $2-2.5$ meters and is layered. The bank materials were classified based on samples of bank material collected from two perpendicular segments of the bank (Table 1). Three dissimilar deposits were recognized (from the base upwards) as follows:

$>1 \mathrm{~m}$ thick grey sand with silt,

$1 \mathrm{~m}$ thick clayey silt with sand,

$0.4 \mathrm{~m}$ thick brown sand with silt.

An initial geotechnical classification of these bank materials was undertaken by means of a variety of in-situ investigations that comprised leakage tests for defining the saturated hydraulic conductivity (Amoozegar, 1989), Borehole Shear Tests (Lutenegger \& Hallberg, 1981), and matric suction measurements using a tensiometer. The fluvial erodibility coefficient, as well as the critical shear stress, were found out by in situ jet tests (Hanson \& Simon, 2001) using a non-vertical jet test device (Dapporto, 2001). A summary of the measured geotechnical properties and erodibility data is provided in Table 2.

\section{Monitoring Activity}

Field data collection was necessary to set-up the CFD models used in this study. To characterize the bathymetry of the study reach, a high-resolution tachometric survey was undertaken. The total number of points surveyed was 2313 over an

Table 1. River Asker grain size data.

\begin{tabular}{cccc}
\hline Materials & Grey sand with silt & Red silt with sand & Brown sand with silt \\
\hline Sand (\%) & 59.4 & 41.8 & 57.9 \\
Silt (\%) & 37.5 & 52.0 & 38.2 \\
Clay (\%) & 3.1 & 6.2 & 2.7 \\
$\mathrm{D}_{16}(\mathrm{~mm})$ & 0.017 & 0.008 & 0.013 \\
$\mathrm{D}_{50}(\mathrm{~mm})$ & 0.073 & 0.050 & 0.064 \\
$\mathrm{D}_{84}(\mathrm{~mm})$ & 0.135 & 0.100 & 0.158 \\
\hline
\end{tabular}

Table 2. River Asker geotechnical properties and erodibility parameters.

\begin{tabular}{cccc}
\hline Parameter & Grey sand with silt & Red silt with sand & Brown sand with silt \\
\hline Volumetric water content (\%) & 44.0 & 43.0 & 33.2 \\
Bulk unit weight $\left(\mathrm{kN} / \mathrm{m}^{3}\right)$ & 18.0 & 17.9 & 18.0 \\
Dry unit weight $\left(\mathrm{kN} / \mathrm{m}^{3}\right)$ & 13.7 & 13.7 & 14.7 \\
Saturated permeability $(\mathrm{m} / \mathrm{s})$ & $3.5 \times 10^{-8}$ & $5.6 \times 10^{-10}$ & $4.2 \times 10^{-6}$ \\
$\quad$ Friction angle $\left(^{\circ}\right)$ & 28.1 & 39.4 & 38.4 \\
Apparent cohesion $(\mathrm{kPa})$ & 2.4 & 2.2 & 1.6 \\
Erodibility coefficient $\left(\mathrm{m}^{3} / \mathrm{Ns}\right)$ & $9.5 \times 10^{-5}$ & $5.9 \times 10^{-6}$ & - \\
Critical shear stress $(\mathrm{Pa})$ & 0.29 & 2.35 & -
\end{tabular}


area of $2512 \mathrm{~m}^{2}$. Accordingly, the spatial resolution of the source topographic information was almost $1 \mathrm{~m}^{2}$ (one point per square meter). These survey points were used to create a Digital Elevation Model (DEM) for later use in CFD mesh generation (Figure 2).

Flow discharge values were retrieved from the nearest gauging station. Water surface elevations within the study reach were demarcated utilizing a system of ten crest stage gauges spread out at twenty meter intervals along the reach (see Figure 2 for locations). A crest gauge is a small diameter pipe mounted vertically in the stream, capped on the bottom, with several holes to allow water to enter. Finely ground cork is placed at the base of the pipe and a wood rod is placed on the inside of the pipe. When high water occurs, the cork floats on the water that flows into the pipe, thereby leaving a ring on the wood rod at the maximum water height.

Flow velocimetry data, under low flow conditions, was acquired using a two component electromagnetic current meter (ECM) in January 2004. These data were collected at 65 locations over the reach for the purpose of validating the CFD model outputs. At each of these 65 locations, a vertical profile was taken containing three points located close to the bed, in the mid-portion of the flow and near the surface, respectively. The majority of the field observations were undertaken, for each point, at $\mathrm{Z} / \mathrm{H}$ values, where $\mathrm{Z}$ is the local flow depth of the measurement and $\mathrm{H}$ represents the total flow depth at that position, of $0.2,0.6$, and 0.8. This technique delivered a well-distributed network of 195 points at which flow velocity was measured within the examined stretch.

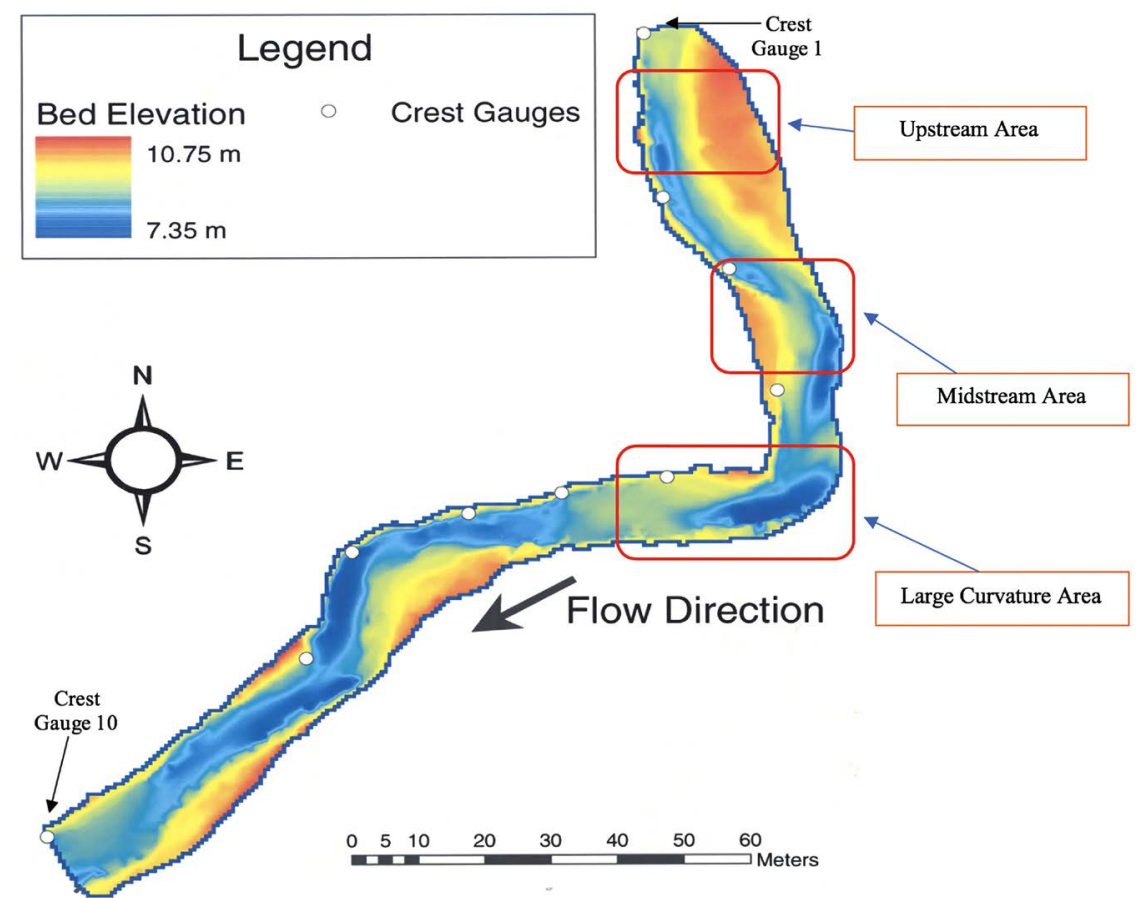

Figure 2. Crest-gauges locations and bed elevations of the study reach (based on February 2004 survey). Also shown are the locations (upstream, midstream, and large curvature areas) of focus study areas discussed in detail in the results. 
A variety of flow discharge events, with estimated return intervals ranging from nearly 1 to 10 years, were captured during the monitoring period (Table $3)$. Water surface elevations recorded for the two examined flow events are detailed in Table 4.

\section{Model Set-Up and Validation}

The modelling conducted here was developed using existing CFD software implemented to represent the stretch of the River Asker for the two specific flow events (high flow event: HFE and low flow event: LFE) summarized in Table 3. These specific flow events were selected for analysis here because they represent a wide range of peak flow discharges (from 0.791 to $18.4 \mathrm{~m}^{3} / \mathrm{s}$ ), with estimated recurrence intervals from $<1$ year to $\sim 8$ years, respectively. Simulations were established using Fluent 6.2 (Fluent Inc., 2006), whereas for the geometry and mesh generation two pre-processing programs were engaged, specifically, Gambit 2.1 (Fluent Inc., 2006) and Harpoon (Sharc Ltd., 2006). Before choosing the appropriate turbulence model several runs were executed, in which the use of almost all the available turbulence closures within Fluent 6.2 were compared. This was done to define the significance of the different turbulent closures when simulating flows in rivers. More specifically, the simulations were carried out by employing four different models, namely, the standard $k-\varepsilon$, the RNG $k-\varepsilon$, the standard k- $\omega$, and the SST k- $\omega$. The results were compared with the field data. The latter analysis revealed that the results obtained using the standard $k-\varepsilon$ turbulence model gave the best fit compared to the field data.

Validation of the time-averaged flow structures under the LFE simulations is expanded in this section by comparing the measured and modelled flow velocity data acquired at the 65 field measurement stations (see previous section for details). The validation exercise focused on the overall River Asker reach, but also it is undertaken specifically for the three areas of interest (AOIs) shown in Figure 2 (namely the upstream area, midstream area, and large curvature area). These areas were selected for focused investigation to determine if model performance varied in areas of the channel with different planform attributes. An

Table 3. Features of the examined flow occasions.

\begin{tabular}{|c|c|c|c|c|c|c|}
\hline Flow Events & $\begin{array}{l}\text { Acronyms } \\
\text { used in Text }\end{array}$ & Date of Flow & $\begin{array}{c}\text { Peak Flow } \\
\text { Discharge }\left(\mathrm{m}^{3} / \mathrm{s}\right)\end{array}$ & $\begin{array}{c}\text { Water Elevation at } \\
\text { Upstream Boundary }(\mathrm{m})\end{array}$ & $\begin{array}{c}\text { Average Water Surface } \\
\text { Gradient }(\mathrm{m} / \mathrm{m})\end{array}$ & $\begin{array}{c}\text { Estimated Recurrence } \\
\text { Interval (years) }\end{array}$ \\
\hline Low Flow Event & LFE & 5 Jan. 2004 & 0.8 & 9.250 & 0.0030 & - \\
\hline High Flow Event & HFE & 12 Jan. 2004 & 18.4 & 10.240 & 0.0030 & 8 \\
\hline
\end{tabular}

Table 4. Water surface elevation information acquired from the ten crest gauges.

\begin{tabular}{ccccccccccc}
\hline & \multicolumn{10}{c}{ Observed Water Surface Elevation (m) } \\
\hline Crest Gauges & $\mathbf{1}$ & $\mathbf{2}$ & $\mathbf{3}$ & $\mathbf{4}$ & $\mathbf{5}$ & $\mathbf{6}$ & $\mathbf{7}$ & $\mathbf{8}$ & $\mathbf{9}$ & $\mathbf{1 0}$ \\
LFE & 9.25 & 9.18 & 9.1 & 9.03 & 8.96 & 8.92 & 8.85 & 8.78 & 8.76 & 8.42 \\
HFE & 10.24 & 10.11 & 10.06 & 10.02 & 9.95 & 9.93 & 9.92 & 9.81 & 9.68 & 9.6 \\
\hline
\end{tabular}


overall global assessment of predicted against observed downstream and transverse velocity components was undertaken in Figure 3. A local analysis within the remaining three AOIs is illustrated in Figures 4-6, respectively. Both the global and regional analyses are undertaken for each of the three $\mathrm{Z} / \mathrm{H}$ levels measured in the field. As a result, any inaccuracies that vary as a function of the flow depth can be recognized. This procedure delivers a comprehensive assessment of the skill of the model to replicate the measured flow velocity fields.

As can be seen in Figure 3(a) there is good qualitative agreement between the simulated and measured downstream velocity components, especially for $\mathrm{Z} / \mathrm{H}$ values of 0.2 , and $0.8\left(R^{2}=0.88\right.$ and $R^{2}=0.88$, respectively), albeit the model performs slightly less well for the $\mathrm{Z} / \mathrm{H}$ value of $0.6\left(\mathrm{R}^{2}=0.72\right)$. The same trend is observed in the midstream area (Figure $5(\mathrm{a}))$ where at $\mathrm{Z} / \mathrm{H}$ values of $0.2\left(\mathrm{R}^{2}=\right.$ $0.82)$ and $0.8\left(R^{2}=0.82\right)$ the model replicates the measured field data well, but at

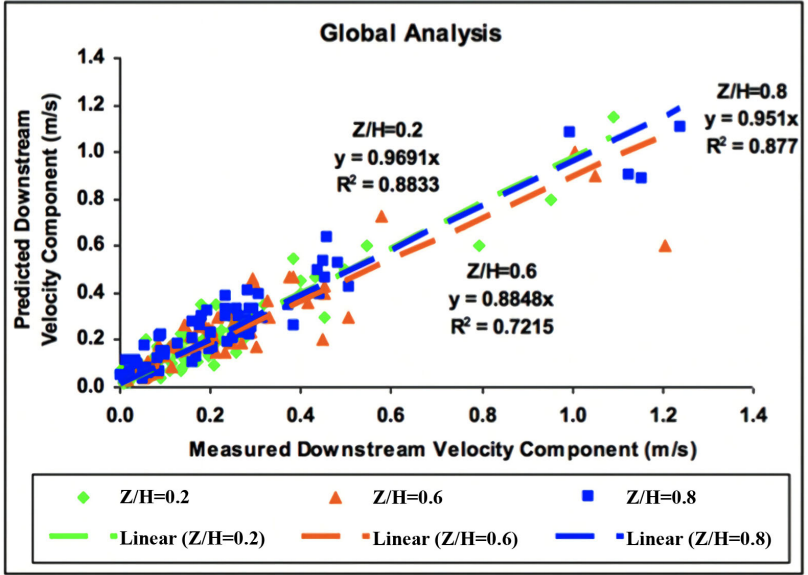

(a) Downstream Velocity Component

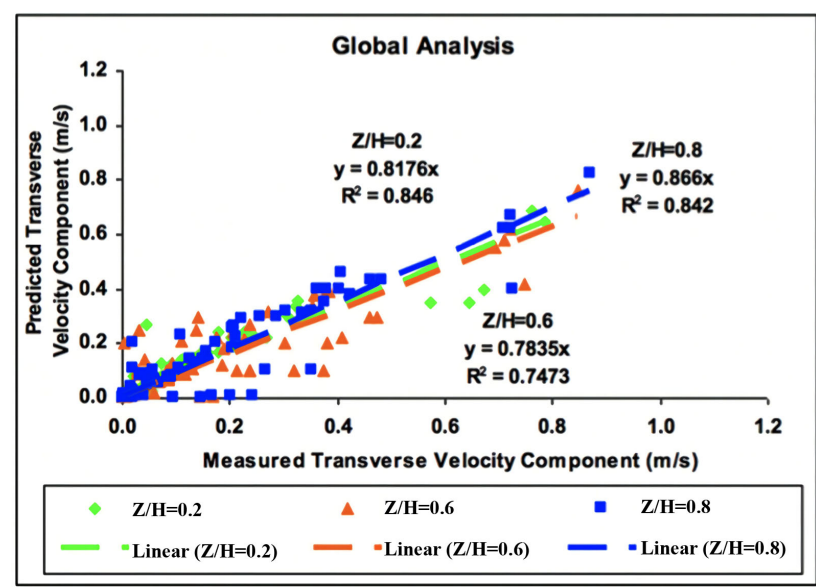

(b) Transverse Velocity Component

Figure 3. Global examination of predicted against measured (a) downstream and (b) transverse velocity components related to all measurement locations within the River Asker stretch.

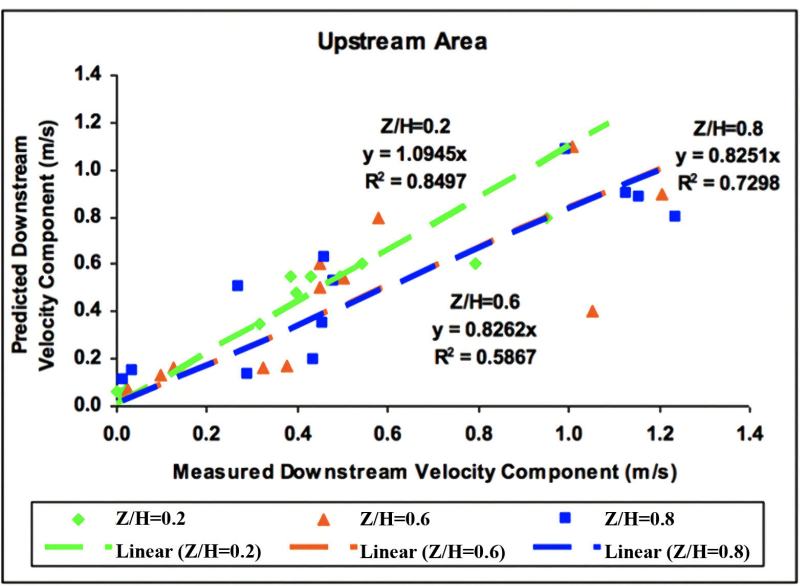

(a) Downstream Velocity Component

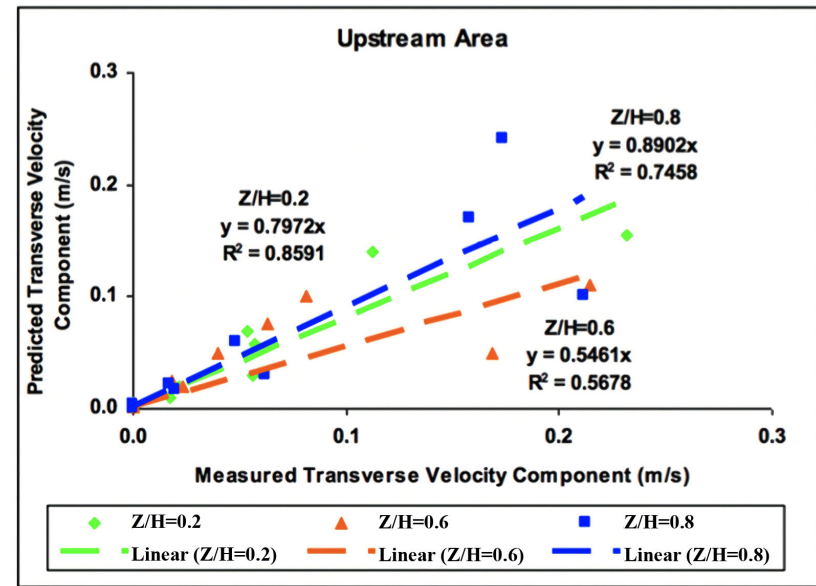

(b) Transverse Velocity Component

Figure 4. Regional examination of predicted against measured (a) downstream and (b) transverse velocity components related to the upstream area of interest (see Figure 2 for location). 


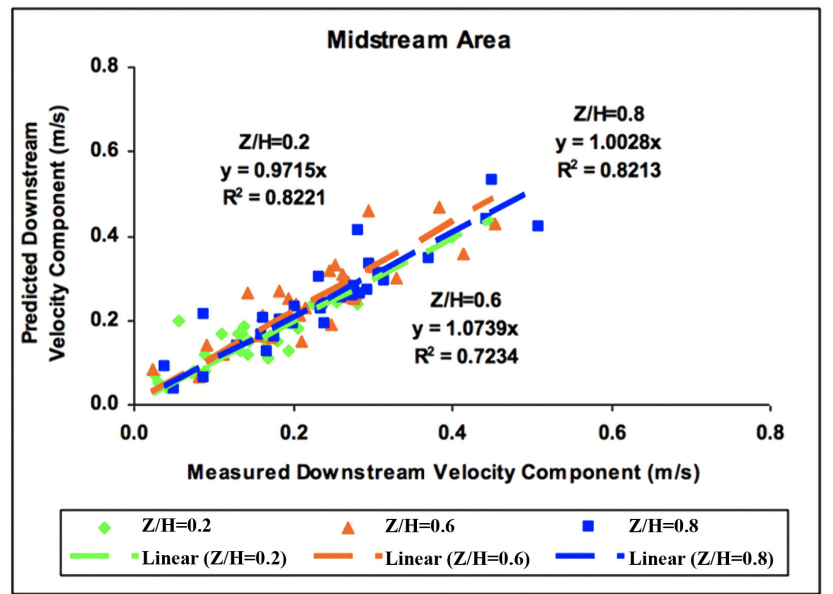

(a) Downstream Velocity Component

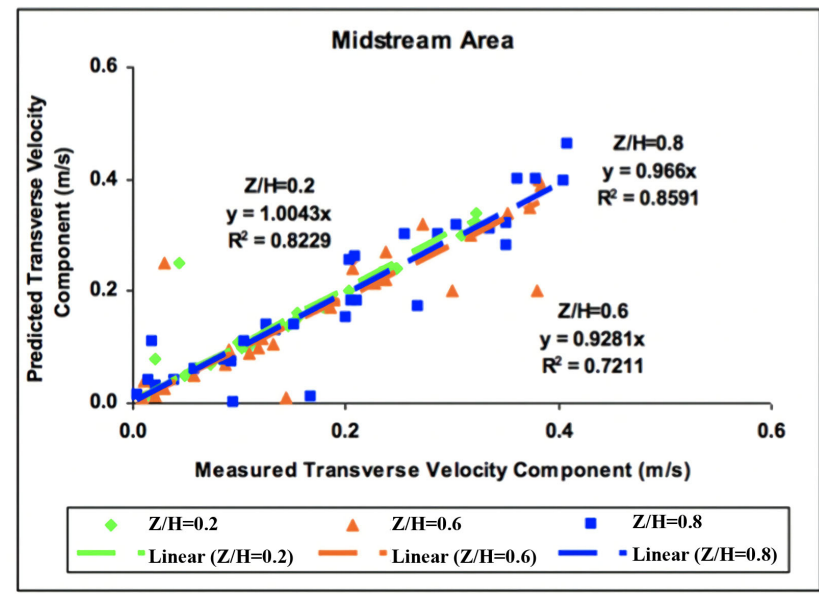

(b) Transverse Velocity Component

Figure 5. Regional examination of predicted against measured (a) downstream and (b) transverse velocity components related to the midstream area of interest (see Figure 2 for location).

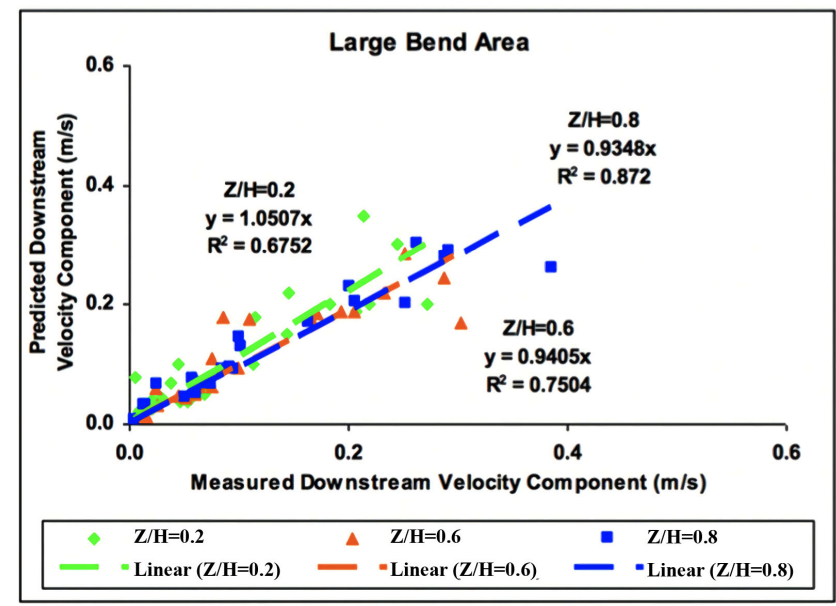

(a) Downstream Velocity Component

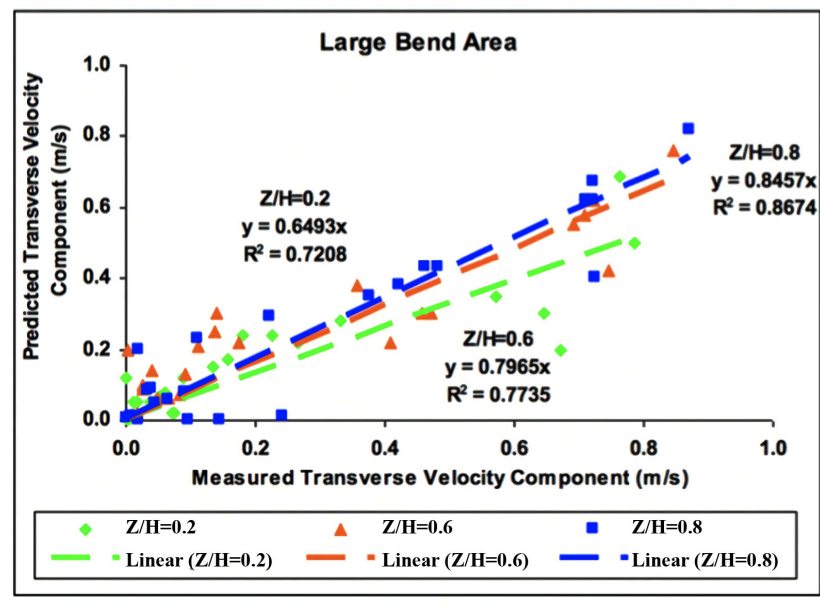

(b) Transverse Velocity Component

Figure 6. Regional examination of predicted against measured (a) downstream and (b) transverse velocity components related to the large curvature area of interest (see Figure 2 for location).

a $\mathrm{Z} / \mathrm{H}$ value of $0.6\left(\mathrm{R}^{2}=0.72\right)$ there is good, but nevertheless weaker, agreement. In the upstream area (Figure $4(\mathrm{a})$ ) the model performs well for $\mathrm{Z} / \mathrm{H}$ value of 0.2 $\left(\mathrm{R}^{2}=0.85\right)$, while it performs less well for $\mathrm{Z} / \mathrm{H}$ values of $0.6\left(\mathrm{R}^{2}=0.59\right)$ and 0.8 $\left(R^{2}=0.73\right)$. Finally, in the large bend area (Figure $\left.6(\mathrm{a})\right)$ there is good qualitative validation for $\mathrm{Z} / \mathrm{H}$ values of $0.8\left(\mathrm{R}^{2}=0.87\right)$ but the model perform less well for $\mathrm{Z} / \mathrm{H}$ values of $0.2\left(\mathrm{R}^{2}=0.67\right)$ and $0.6\left(\mathrm{R}^{2}=0.75\right)$.

As can be also seen in Figure 3(b) there is also a good agreement between the measured and simulated transverse velocity component for the data points corresponding to $Z / H$ values of 0.2 , and $0.8\left(R^{2}=0.85\right.$ and $R^{2}=0.84$, respectively) but the model perform less well for the $\mathrm{Z} / \mathrm{H}$ value of $0.6\left(\mathrm{R}^{2}=0.75\right)$. The same tendency is witnessed in the upstream area (Figure $4(\mathrm{~b})$ ) for the transverse velocity component where at $\mathrm{Z} / \mathrm{H}$ values of $0.2\left(\mathrm{R}^{2}=0.86\right)$ the model replicates the 
measured field data well, but at $\mathrm{Z} / \mathrm{H}$ values of $0.6\left(\mathrm{R}^{2}=0.57\right)$ and $0.8\left(\mathrm{R}^{2}=0.75\right)$ there is weaker performance. At the midstream area (Figure $5(\mathrm{~b})$ ) the model again performs well for $\mathrm{Z} / \mathrm{H}$ values of $0.2\left(\mathrm{R}^{2}=0.82\right)$ and $0.8\left(\mathrm{R}^{2}=0.86\right)$ while less so for a $\mathrm{Z} / \mathrm{H}$ value of $0.6\left(\mathrm{R}^{2}=0.72\right)$. Lastly, in the large bend area (Figure $6(\mathrm{~b}))$ there is good agreement for a $\mathrm{Z} / \mathrm{H}$ value of $0.8\left(\mathrm{R}^{2}=0.87\right)$ and good, but weaker, agreement for $\mathrm{Z} / \mathrm{H}$ values of $0.2\left(\mathrm{R}^{2}=0.72\right)$ and $0.6\left(\mathrm{R}^{2}=0.78\right)$.

Overall, the results of the validation exercise lend confidence that the numerical simulations are sufficiently reliable that they can be used to explore the actual flow velocity fields experienced in reality.

\section{Modelling Results: Low Flow Event (LFE)}

Considerations of flow structures in river channel landscapes such as meander bends, confluences and braids, have usually been based on comprehensive field measurements (Dietrich \& Smith, 1984; Ashmore et al., 1992; Rhoads \& Sukhodolov, 2001). Outcomes have usually been pictured by means of cross-section plots of the stream wise velocity component overlain with vectors to represent the transverse and vertical flow, so as to recognize configurations of the secondary circulation (Lane et al., 1999b). A downstream arrangement of such schemes is frequently utilized to visualize the synoptic nature of stream wise variations in the flow.

In this paper planform diagrams demonstrating the spatial configurations of the near to bed $(\mathrm{Z} / \mathrm{H}=0.2)$ and near to surface $(\mathrm{Z} / \mathrm{H}=0.8)$ velocity magnitude in the form of velocity vectors overlain on contours of velocity magnitude are presented.

To assist in visualizing the specific flow events for the LFE, four areas of interest, namely, upstream inflow zone, midstream small curve zone, upstream large curve zone, and downstream large curve zone, were documented (Figure 7). These four areas of interest were selected because they represent diverse areas through the stretch expressive of several different flow configurations.

The simulated flow configurations of the near-bed $(\mathrm{Z} / \mathrm{H}=0.2)$ and near-surface $(\mathrm{Z} / \mathrm{H}=0.8)$ velocity magnitudes with velocity vectors for the four areas of interest are shown in Figure 8 (areas of interest 1 and 2) and Figure 9 (areas of interest 3 and 4). The flow characteristics in all areas of interest were discussed in detail at three cross sections labelled as A-C in the downstream direction. In addition, contours of near surface velocity magnitudes in each of the four areas of interest for the LFE are shown in Figure 10.

Flow features in area of interest 1 were identified by considering three different cross sections within the upstream inflow zone (Figure 8(a) \& Figure 8(b)), labelled A-C in downstream order. As indicated in Figure 8(a) \& Figure 8(b), there is a clear deceleration of the flow towards the right bank. More specifically, between sections A and B the near bed velocity is much higher at the shallow riffle close to the left bank $(\sim 0.8 \mathrm{~m} / \mathrm{s})$ than at the deeper pool towards the right bank $(\sim 0.2 \mathrm{~m} / \mathrm{s})$. In contrast, the near surface flow corresponding at the same 


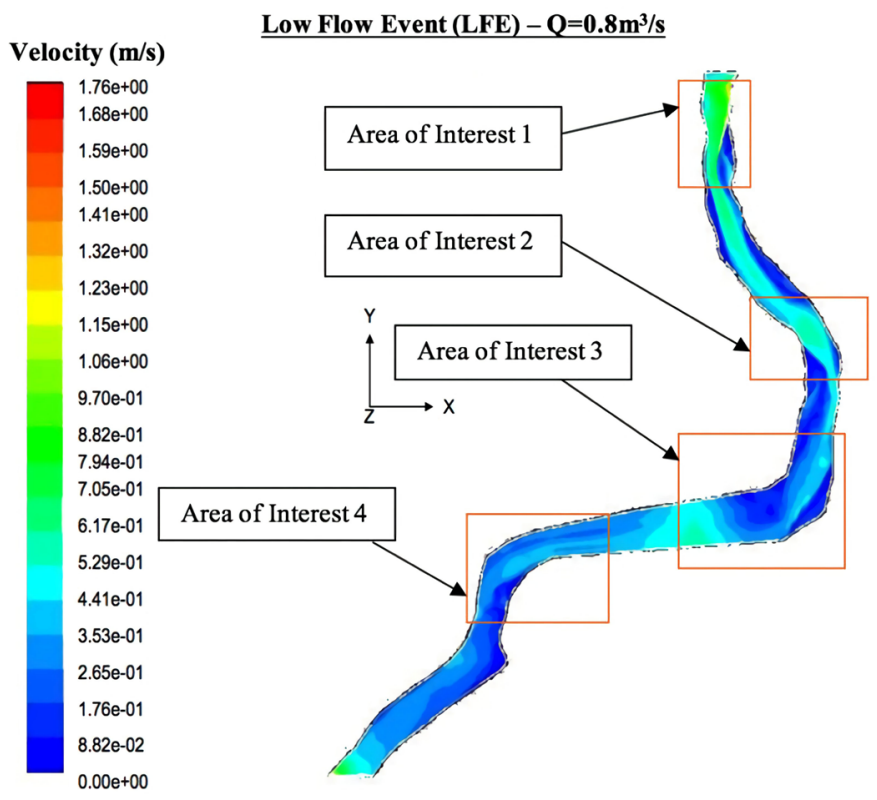

Figure 7. Planform view of near surface $(\mathrm{Z} / \mathrm{H}=0.8)$ velocity magnitude for the River Asker stretch under LFE $\left(\mathrm{Q}=0.8 \mathrm{~m}^{3} / \mathrm{s}\right)$ presenting the four areas of interest.
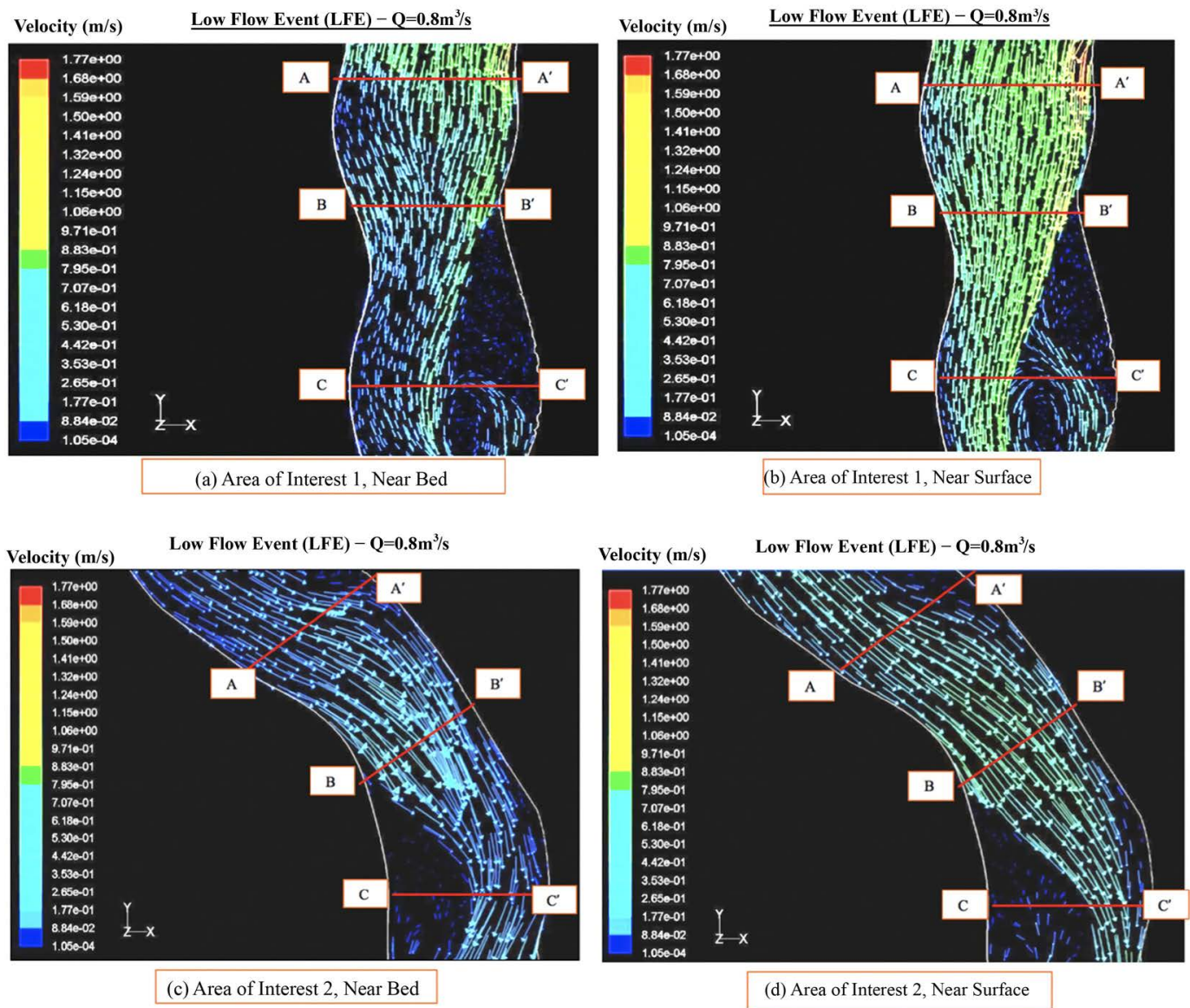

Figure 8. Simulated velocity magnitude with velocity vectors displaying flow direction near bed $(\mathrm{Z} / \mathrm{H}=$ $0.2)$ and near surface $(\mathrm{Z} / \mathrm{H}=0.8)$ for Areas of Interest $1(\mathrm{a}, \mathrm{b})$ and $2(\mathrm{c}, \mathrm{d})$ under low flow conditions, $\mathrm{Q}=$ $0.8 \mathrm{~m}^{3} / \mathrm{s}$. See Figure 7 for the locations of the Areas of Interest. 


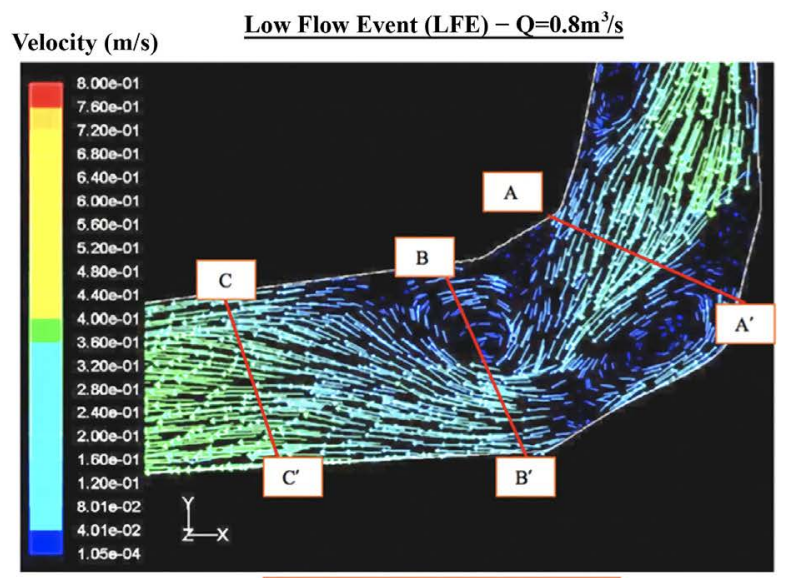

(a) Area of Interest 3, Near Bed

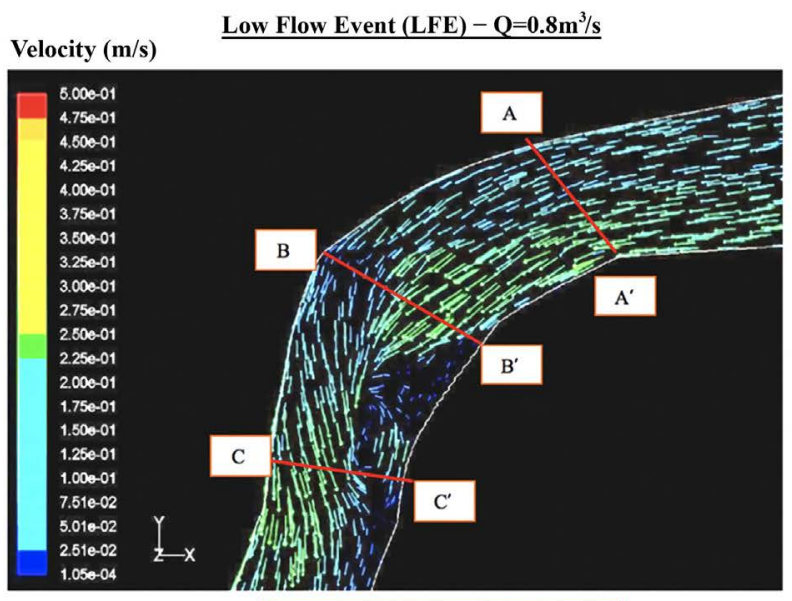

(c) Area of Interest 4, Near Bed

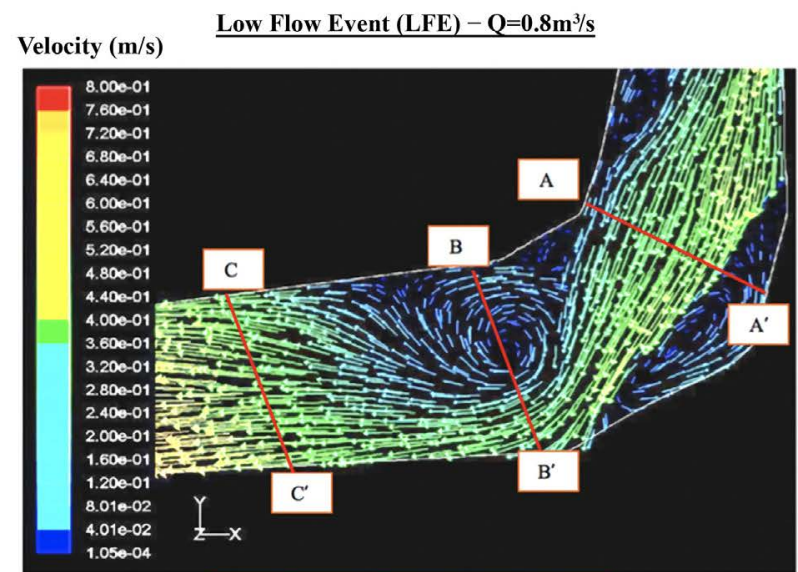

(b) Area of Interest 3, Near Surface

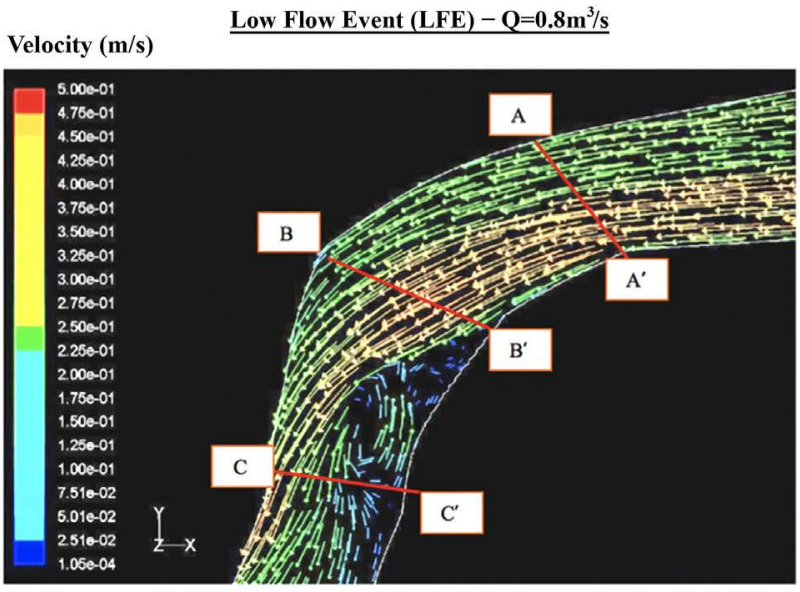

(d) Area of Interest 4, Near Surface

Figure 9. Simulated velocity magnitude with velocity vectors displaying flow direction near bed $(\mathrm{Z} / \mathrm{H}=0.2)$ and near surface $(\mathrm{Z} / \mathrm{H}=0.8)$ for Areas of Interest $3(\mathrm{a}, \mathrm{b})$ and $4(\mathrm{c}, \mathrm{d})$ under low flow conditions, $\mathrm{Q}=0.8 \mathrm{~m}^{3} / \mathrm{s}$. See Figure 7 for the locations of the Areas of Interest.

locations decelerates from $\sim 0.8 \mathrm{~m} / \mathrm{s}$ at the shallow riffle to $\sim 0.3 \mathrm{~m} / \mathrm{s}$ very close to the right bank.

The left side of the channel between sections $\mathrm{B}$ and $\mathrm{C}$ is shown to be a dead zone of stagnant flow $(<0.1 \mathrm{~m} / \mathrm{s}$ at both the surface and the bed). The near bed fast flow $(\sim 0.8 \mathrm{~m} / \mathrm{s})$ is mainly concentrated into the central area in the form of a small stream tube, while the near surface flow is extended towards the right bank at almost the same intensity $(\sim 0.9 \mathrm{~m} / \mathrm{s})$. A recirculation zone comes close to the middle part of cross-section $\mathrm{C}$ within the dead flow zone, although the near surface and near bed isovels have different patterns leading to a helicoidal flow. The region of stagnant flow, within which a zone of flow separation occurs, is extensive. The separated zone has a clockwise circulation in plan view. Low near surface velocities $(\sim 0.5 \mathrm{~m} / \mathrm{s})$ merged with the main flow after recirculating, while near bed flow velocities at the same location are smaller and do not return to the fast near bed stream tube. 

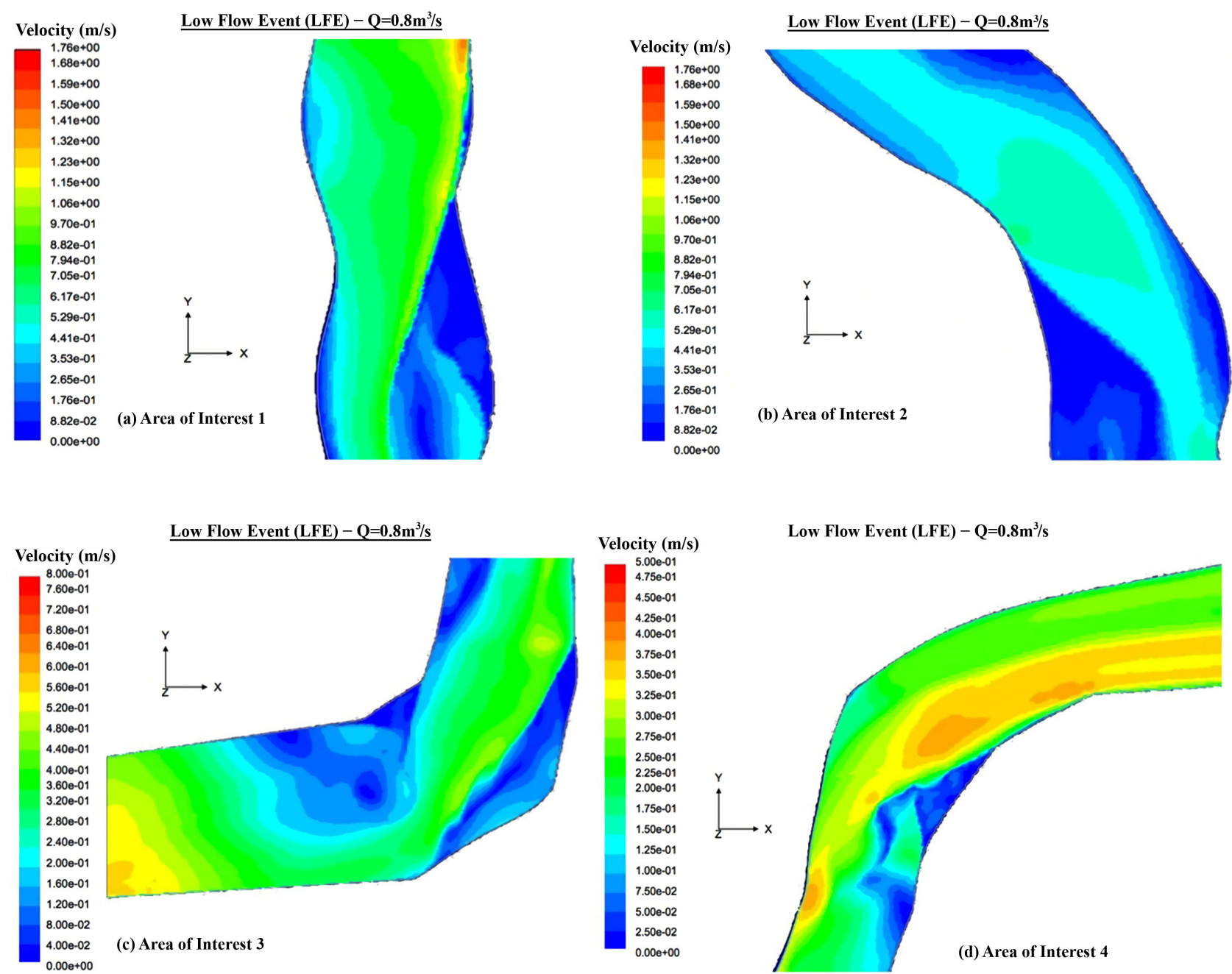

Figure 10. Simulated near surface $(\mathrm{Z} / \mathrm{H}=0.8)$ velocity magnitude for Areas of Interest $1(\mathrm{a}), 2(\mathrm{~b}), 3(\mathrm{c})$, and 4 (d) under low flow conditions, $\mathrm{Q}=0.8 \mathrm{~m}^{3} / \mathrm{s}$. See Figure 7 for locations of the areas of interest.

The down channel flow between sections A and B at the location that is approximately mid-way towards the right bank has also the classic characteristics of helicoidal flow, with bed vectors angled leftwards but the surface vectors remaining straight in place. The interpretation of secondary circulation is based upon the differences between the near bed and the near surface velocity magnitude and direction. In this particular case, the difference in direction is as much as 45 degrees, whereas the velocity component at the surface can exceed $0.8 \mathrm{~m} / \mathrm{s}$ in a straight line but at the bed can exceed $0.4 \mathrm{~m} / \mathrm{s}$ to the left. The second area of significant secondary circulation can be found in the right-hand half of the channel, downstream of section C. Its characteristics are similar to those for the one previously discussed, with magnitudes of surface velocity more than $0.8 \mathrm{~m} / \mathrm{s}$ flowing forwards and magnitudes of bed velocity component at approximately $0.3 \mathrm{~m} / \mathrm{s}$ to the left.

Simulated near-bed and near-surface flow patterns within area of interest 2 (midstream small curve zone) are illustrated in Figure 8(c) \& Figure 8(d). 
Three cross-sections (labelled A-C in downstream order) were again drawn within the midstream small bend area to make reference to the various flow features easier.

Two regions corresponding to the characteristic helicoidal flow are identified within the stream tube of relatively fast down channel flow. The first one is located on the left-hand side of section A, with bed vectors angled towards, but surface vectors forced parallel to, the outer bank. The difference in direction is as much as 45 degrees. As can be seen the velocity component at the surface can exceed $0.7 \mathrm{~m} / \mathrm{s}$ but at the bed it can exceed $0.4 \mathrm{~m} / \mathrm{s}$ to the left. The second is close to the outer bank in the midstream portion of the small bend, where the helical motion is at a maximum. This strong helical circulation, looking downstream, is evident in the left half of the channel between sections B and C. This second area of significant secondary flow includes several places where surface vectors are angled towards the outer bank $(\sim 0.8 \mathrm{~m} / \mathrm{s}$ to the left) and bed vectors are angled away towards the inner bank $(0.4 \mathrm{~m} / \mathrm{s}$ to the right).

Figure 9(a) \& Figure 9(b) depicts the simulated near-bed and near-surface flow patterns corresponding to area of interest 3 (upstream large curve zone). In this zone there is a general decrease in both the bed and surface velocity $(<0.2$ $\mathrm{m} / \mathrm{s}$ ) at the outer bank bend apex between sections A and B. Low velocities are also simulated downstream of the inner bank bend apex $(<0.2 \mathrm{~m} / \mathrm{s})$. Significant re-circulation zones are developed within those two areas of stagnant flow with near surface and near bed vectors having similar patterns with regards to both their flow direction and magnitude. The periphery of the inner bank re-circulation zone comes close to the outer bank at section B near the outer bend apex, while it spreads almost up to the right-hand corners of sections A, and C. A narrow zone of fast flow is concentrated between the two re-circulation zones. Both the magnitude and the direction of the bed and surface velocities differ considerably within this fast flow zone. A zone of flow separation occurs within the outer bank stagnant flow area after the bend apex towards section $B$. The surface vectors are angled towards the outer bank, while the bed vectors are angled away. This feature is produced by the contrast between outwards flow at the surface and inwards flow at the bed and is essentially the same as in the classical model of curvature-induced flow structure in bends. Flow reattachment is located between sections B and C, midway between the outer bend apex and the end of the model domain. At this stage, the flow is expanded to the whole width of the channel with varying bed $(\sim 0.3 \mathrm{~m} / \mathrm{s})$ and surface $(\sim 0.5 \mathrm{~m} \mathrm{~m} / \mathrm{s})$ velocity magnitudes.

To aid reference to the details of simulated flow features within the downstream bend (area of interest 4), three cross-section lines are marked on the maps (Figure 9(c) \& Figure 9(d)) and labelled A-C in downstream order. Section A runs across the fast flow zone not far from the inflow, B just above the recirculation zone, and $\mathrm{C}$ just downstream of the flow reattachment point. As shown on Figure 9(c) \& Figure 9(d), there is an acceleration of the flow towards 
the bend inner bank just before section A. Both the near bed $(\sim 0.2 \mathrm{~m} / \mathrm{s})$ and near surface $(\sim 0.4 \mathrm{~m} / \mathrm{s})$ velocities are higher at the inner bank as the flow enters the bend. In contrast, the flow velocities corresponding to the outer bank of the bend are low. Therefore, the fast flow zone is concentrated towards the inner bank between sections A and B. A dead zone of stagnant flow $(<0.1 \mathrm{~m} / \mathrm{s}$ at both the surface and the bed) is apparent on the left-hand side, starting downstream of section B.

The outer bend apex is dominated by very low near bed velocities. A recirculation zone is located at the point midway between sections B and C. However, within this recirculation zone the near surface and near bed velocities exhibit similar patterns with regards to their direction. The point of flow reattachment is located close to section C. A large region with characteristic helicoidal flow is evident on the right-hand side between sections $\mathrm{B}$ and $\mathrm{C}$ within the relatively fast down channel flow. The helicoidal flow also extends downstream from section C. Near bed velocity vectors are shown to be angled towards the inner (left) bend bank, while near-surface flow vectors are angled away towards the outer (right) bank. The difference in their direction is as much as 45 degrees in some places, where the velocity component at the surface can exceed $0.3 \mathrm{~m} / \mathrm{s}$ to the right but at the bed can exceed $0.2 \mathrm{~m} / \mathrm{s}$ to the left.

The near surface velocity structure is depicted within Figure 10. As can be seen in Figure 10(b), in the area of interest 2, there is a general acceleration of the flow from the upstream to the shallower middle part of the reach, and some subsequent deceleration to the left-hand half of the outflow section as the reach deepens towards the exit. The acceleration is most prominent in the near surface flow where the minimum velocity increases from $\sim 0.6 \mathrm{~m} / \mathrm{s}$ at the inflow just before section A to $\sim 0.9 \mathrm{~m} / \mathrm{s}$ towards the middle part of section $\mathrm{B}$. The fast flow is mostly concentrated towards the outer bank (mostly over $0.8 \mathrm{~m} / \mathrm{s}$ at the surface, $0.5 \mathrm{~m} / \mathrm{s}$ at the bed), which is in stark contrast to the extensive area of slow flow extending across the channel from the inner bank dead zone of stagnant flow after the inner apex in the downstream direction $(<0.1 \mathrm{~m} / \mathrm{s}$ at both surface and bed). Low velocities also extend very close to the outer bank at the start of the flow (near section A) at both bed and surface. In area of interest 3 (Figure $10(c)$ ), the velocity magnitude for all three velocity components is dominated by the horizontal flow. As can be noted in Figure 10(c), the inflow to the bend is dominated by high velocities $(\sim 0.4 \mathrm{~m} / \mathrm{s})$, except at the right bank where the velocity magnitudes are low $(<0.1 \mathrm{~m} / \mathrm{s})$.

Figure 11 presents the overall configuration of bed shear stress simulated for the LFE. Areas of intense shear are located in regions where the slowly re-circulating flow and the fast stream tube coincide. The presence of zones of slow downstream flow at the inner bank apex has significant effects. The velocity arrangements described above mean that the maximum boundary shear stress is located close to the inner bank upstream of the apex (Figure 11(b)). This specific configuration of boundary shear stress deviates from the standard model of 

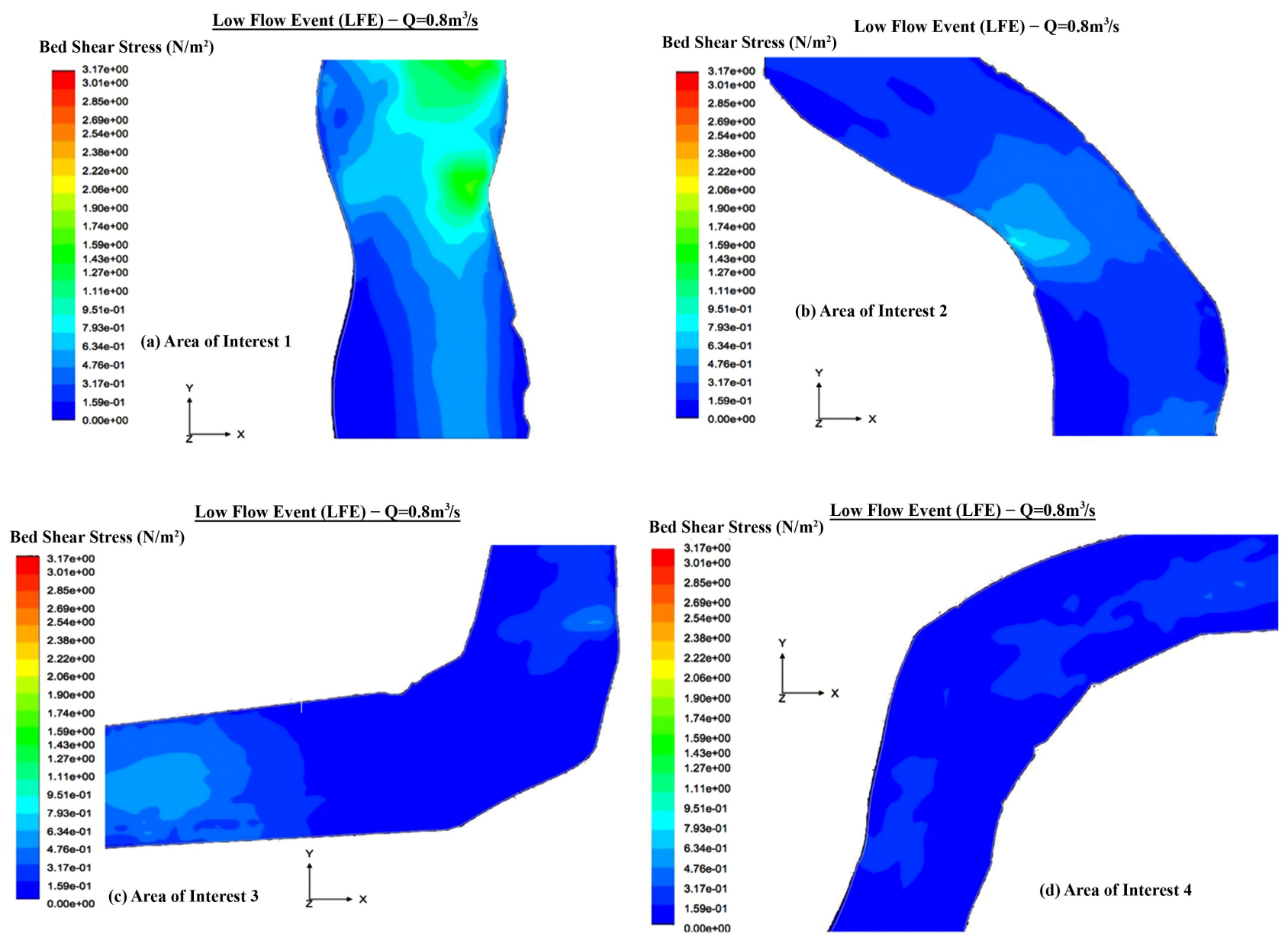

Figure 11. Predicted bed shear stress patterns for Areas of Interest 1 (a), 2 (b), 3 (c), and 4 (d) under low flow conditions $(Q=0.8$ $\left.\mathrm{m}^{3} / \mathrm{s}\right)$.

flow through bends (Dietrich, 1987) in which the zone of maximum shear stress is located adjacent to the outer bank, downstream of the bend apex. There are widespread areas of low boundary shear stresses through the inner bank separation zone that extends downstream of the apex. There are also regions of higher bed shear stresses at the toe of the outer bank located alongside the path of the stream tube. These arrangements have consequences for the sediment dynamics within the bend, bank erosion and meander migration. Understanding in what manner these areas of interest alters necessitates examination of the flow structures at higher flow stages, as detailed in the next section.

\section{Modelling Results: High Flow Event (HFE)}

The three-dimensional time-averaged flow simulated for a near bank full flow event (referred to here as the High Flow Event, HFE) is evaluated in this section (Figure 12).

Simulated near bed and near surface velocity configurations within the four areas of interest are shown in Figure 13 and Figure 14. As with the preceding discussion of the Low Flow Event, the discussion references four areas of interest 


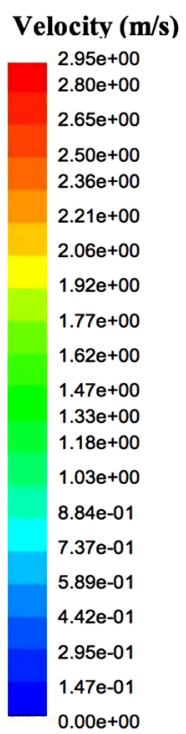

\section{High Flow Event (HFE) - O=18.4 $\mathrm{m}^{3} / \mathrm{s}$}

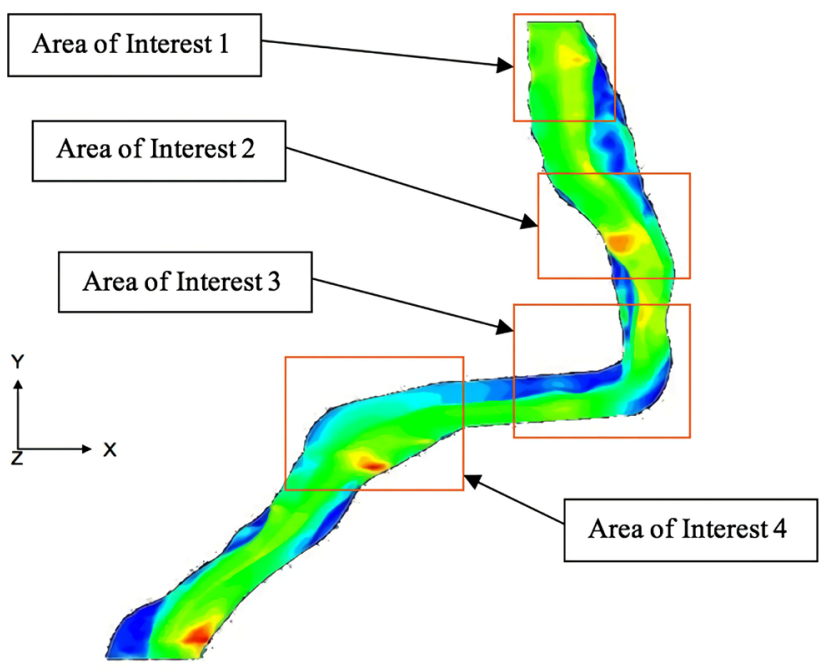

Figure 12. Simulated near surface velocity magnitude for the River Asker stretch under HFE $\left(\mathrm{Q}=18.4 \mathrm{~m}^{3} / \mathrm{s}\right)$, also showing the four areas of interest.

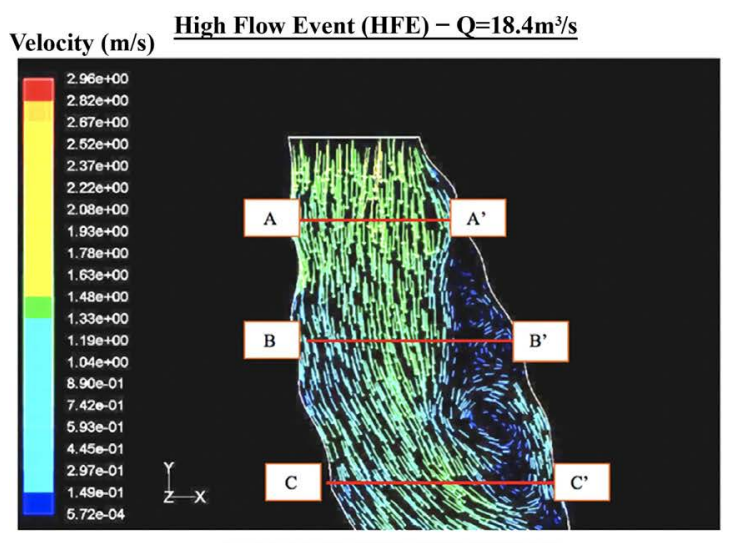

(a) Area of Interest 1, Near Bed

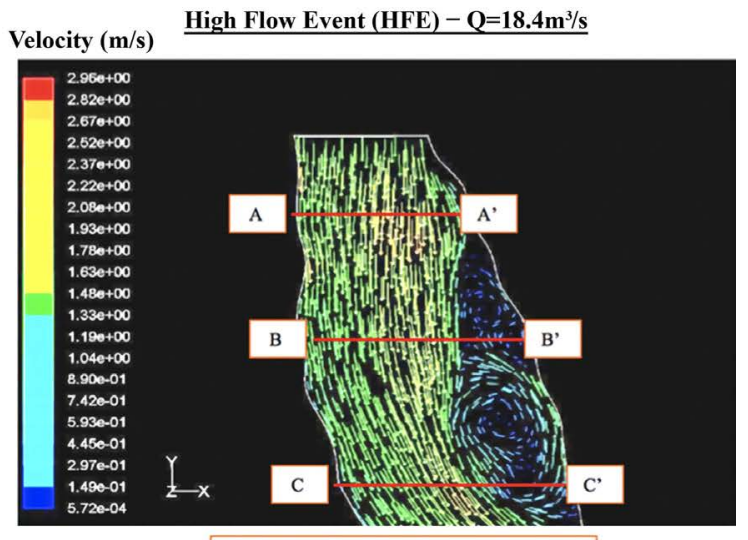

(b) Area of Interest 1, Near Surface

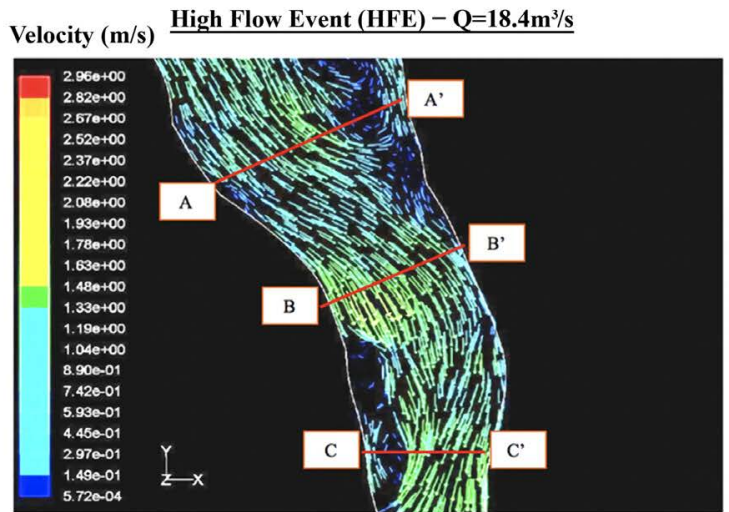

(c) Area of Interest 2, Near Bed

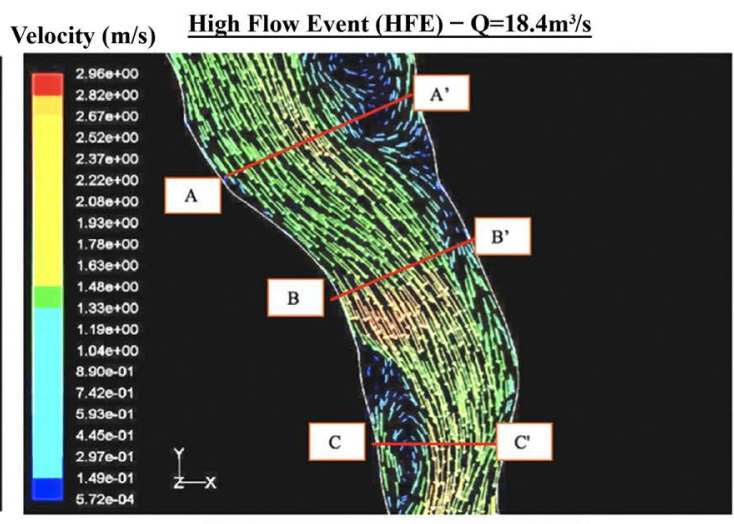

(d) Area of Interest 2, Near Surface

Figure 13. Simulated velocity magnitude with velocity vectors displaying flow direction near bed $(\mathrm{Z} / \mathrm{H}=0.2)$ and near surface $(Z / H=0.8)$ for Areas of Interest $1(a, b)$ and $2(c, d)$ under high flow conditions, $Q=18.4 \mathrm{~m}^{3} / \mathrm{s}$. See Figure 12 for the locations of the Areas of Interest. 


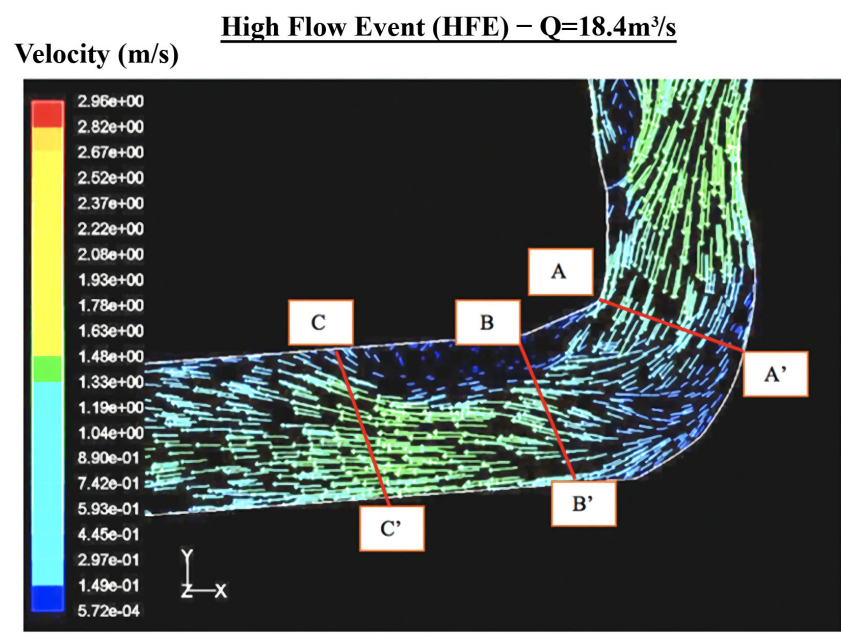

(a) Area of Interest 3, Near Bed

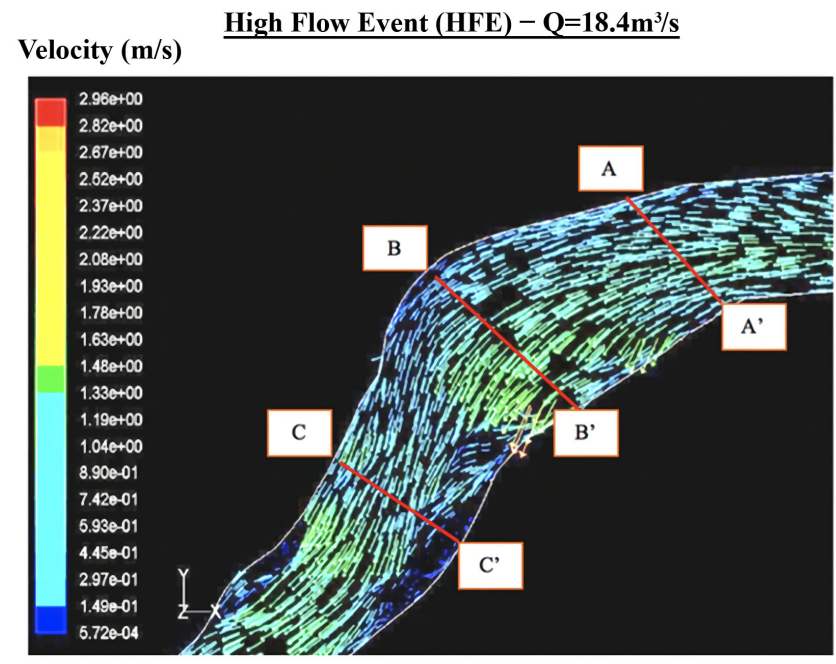

(c) Area of Interest 4, Near Bed

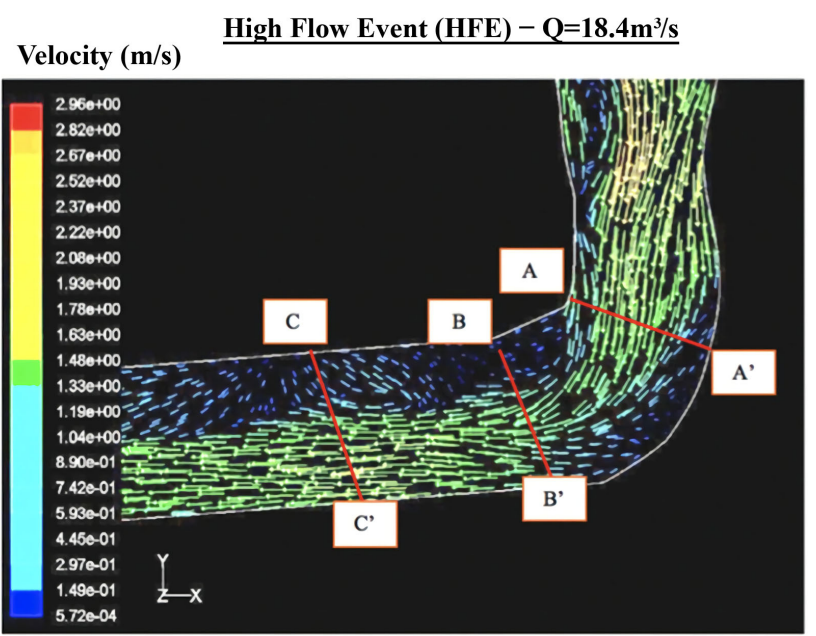

(b) Area of Interest 3, Near Surface

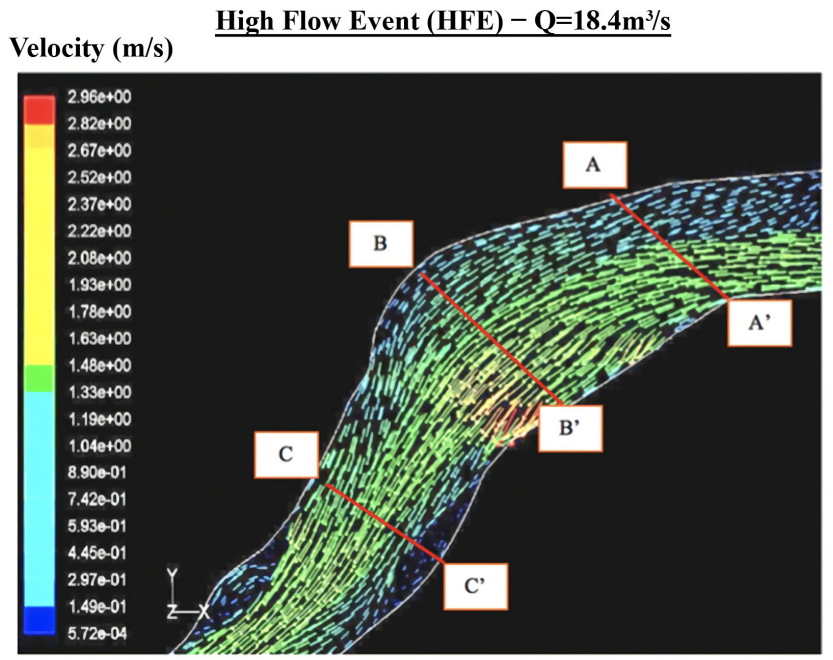

(d) Area of Interest 4, Near Surface

Figure 14. Simulated velocity magnitude with velocity vectors displaying flow direction near bed $(\mathrm{Z} / \mathrm{H}=0.8)$ and near surface $(\mathrm{Z} / \mathrm{H}=0.8)$ for Areas of Interest $3(\mathrm{a}, \mathrm{b})$ and $4(\mathrm{c}, \mathrm{d})$ under high flow conditions, $\mathrm{Q}=18.4 \mathrm{~m}^{3} / \mathrm{s}$. See Figure 12 for the locations of the Areas of Interest.

within each of which three cross sections labelled as A-C in the downstream direction are denoted. The near-surface velocity field within the four areas of interest for the HFE are shown in Figure 15.

Simulated near bed and near surface flow patterns within area of interest 1 are shown in Figure 13(a) \& Figure 13(b). Figure 13(a) \& Figure 13(b) and Figure 15(a) demonstrate that the main features of the flow simulated for the LFE are also maintained at this higher near bank full flow discharge. As flow stage increases, the sloping nature along both banks of the reach, results in a general widening of the channel. A slight deceleration of the flow towards the right bank can be observed in Figure 13(a) \& Figure 13(b). Between sections A and B the near bed velocity is much higher over the shallow riffle close to the left bank 

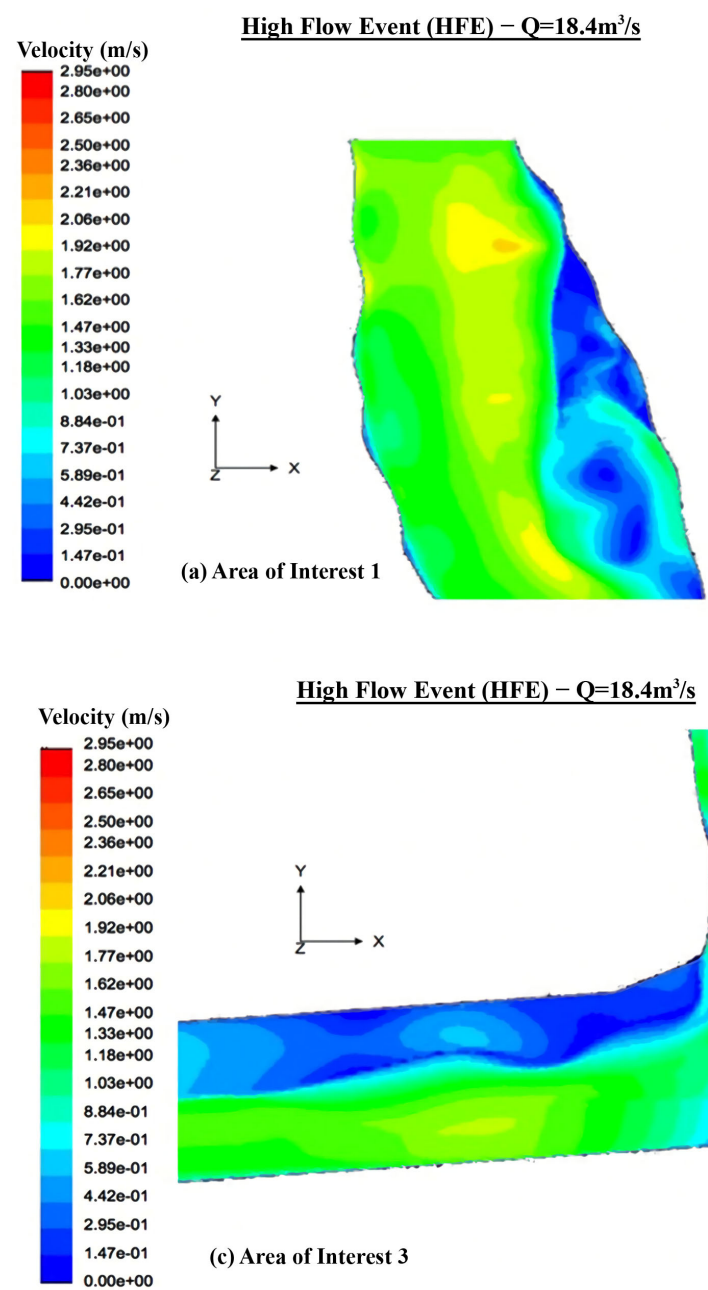

$\underline{\text { High Flow Event (HFE) }-Q=18.4 \mathrm{~m}^{3} / \mathrm{s}}$

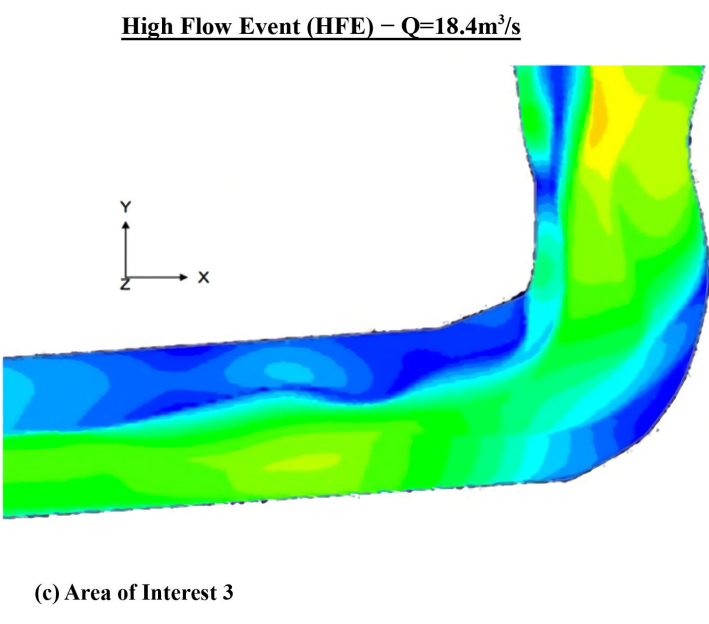

High Flow Event $\left(\right.$ HFE) - Q=18.4m ${ }^{3} / \mathrm{s}$

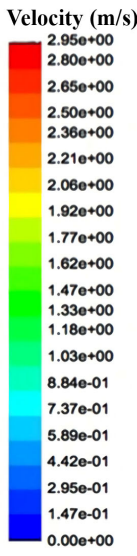

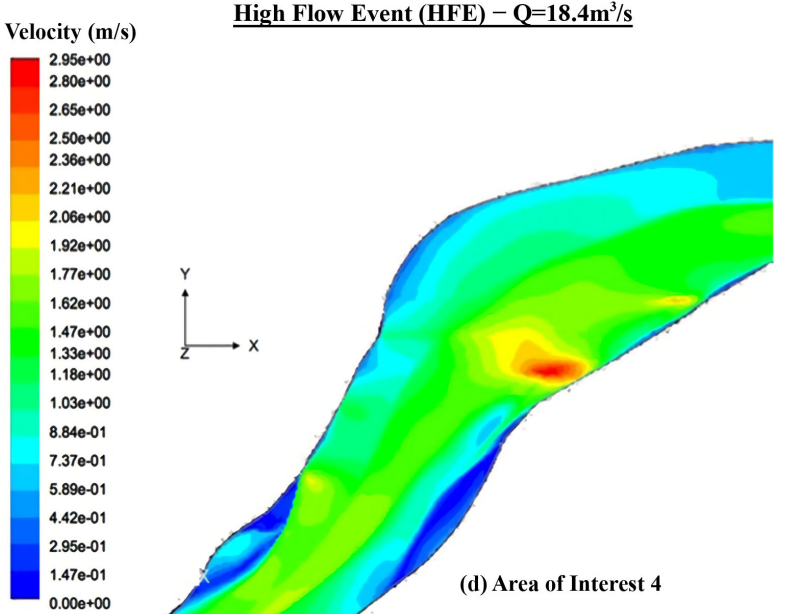

Figure 15. Simulated near surface $(\mathrm{Z} / \mathrm{H}=0.8)$ velocity magnitude for Areas of Interest 1 (a), 2 (b), 3 (c), and 4 (d) under high flow conditions, $\mathrm{Q}=18.4 \mathrm{~m}^{3} / \mathrm{s}$. See Figure 12 for locations of the Areas of Interest.

$(\sim 1.4 \mathrm{~m} / \mathrm{s})$ rather than in the deeper part towards the right bank $(\sim 1.0 \mathrm{~m} / \mathrm{s})$, whereas the near surface flow is shown to be decelerated from $\sim 1.9 \mathrm{~m} / \mathrm{s}$ at the shallow riffle to $\sim 1.3 \mathrm{~m} / \mathrm{s}$ towards the right bank.

In addition, the left side of the channel between sections $\mathrm{A}$ and $\mathrm{B}$ retains a dead zone of stagnant flow $(<0.1 \mathrm{~m} / \mathrm{s}$ at both surface and bed) within which a small zone of flow separation occurs. The fast flow $(\sim 1.7 \mathrm{~m} / \mathrm{s})$ is mainly concentrated into the central area in the form of a small stream tube, with near bed and near surface velocities of $\sim 1.4 \mathrm{~m} / \mathrm{s}$ and $\sim 1.9 \mathrm{~m} / \mathrm{s}$, respectively. A more noteworthy recirculation zone is also observed within the dead flow zone on the left-hand side just downstream of section B. The velocity within this second separation zone is much larger (compared to the LFE) at this near bank full stage, with the flow towards the left bank and the reverse flow at the surface both exceeding a magnitude of $0.8 \mathrm{~m} / \mathrm{s}$. The separated zone has a clockwise circulation in plan view. Near surface velocities merge with the main flow after recirculating, while near bed flow velocities at the same location are smaller and do not fully return to the fast near bed stream tube. 
The simulated near-bed and near-surface flow patterns within area of interest 2 are illustrated in Figure 13(c) \& Figure 13(d). A general widening of the channel along both banks is observed as flow stage increases. However, the main features present in the LFE are again maintained at this near bank full flow discharge. As can be seen in Figure 15(b), there is a general acceleration of the flow from the upstream to the middle part, with a peak at the inner small bend apex and some subsequent deceleration to the left-hand half outflow section of the reach. The acceleration is most prominent in the near surface flow where the maximum velocity increases from $\sim 1.5 \mathrm{~m} / \mathrm{s}$ at the inflow just before section $A$ to $\sim 2.8 \mathrm{~m} / \mathrm{s}$ towards section $\mathrm{B}$, especially along the inner bend apex.

After section B, the fast flow is mostly concentrated towards the outer bank (at speeds in excess of $1.5 \mathrm{~m} / \mathrm{s}$ at the surface, and $1.0 \mathrm{~m} / \mathrm{s}$ at the bed), which is in stark contrast to the extensive area of slow flow extending across the channel from the inner bank dead zone of stagnant flow after the inner apex in the downstream direction $(<0.1 \mathrm{~m} / \mathrm{s}$ at both surface and bed). The mean velocities within area of interest 2 under the near bank full high discharge are much higher than those simulated for the LFE, while impingement of the fast flow core on the outer bank occurs further downstream than at the low flow stage. In addition, a second area corresponding to a separation zone can be found within the stagnant flow after section $\mathrm{C}$. The same regions of the characteristic helicoidal flow identified within the LFE are also observed in this higher flow stage. The first one is located at the right-hand half of section A (next to the recirculation zone). The second one is close to the outer bank in the midstream portion of the small bend, where the helical motion is at a maximum. This strong helical circulation, looking downstream, can be seen in the left-hand half between sections B and C with bed vectors angled towards the inner bank but surface vectors angled towards the outer bank. The difference in direction is as much as 45 degrees with velocity component at the surface exceeding $1.9 \mathrm{~m} / \mathrm{s}$ outwards, but that at bed exceeding $1.1 \mathrm{~m} / \mathrm{s}$ inwards.

Simulated near-bed and near-surface flow patterns within the upstream large bend (area of interest 3) are shown in Figure 14(a) \& Figure 14(b). As also can be noted in Figure 15(c), the inflow to the bend except on the right-hand close to the inner bank is dominated by high velocities $(\sim 2.0 \mathrm{~m} / \mathrm{s})$. At the inner bank the velocity magnitudes are found to be lower. A general deceleration in both bed and surface velocity is observed at the outer bank bend apex between sections A and B, as can be seen in Figure 14(a) \& Figure 14(b). The mean inflow velocity into the bend $(\sim 2.0 \mathrm{~m} / \mathrm{s})$ occupies almost the whole width of the channel, albeit it is focused along the inner bank apex.

The strong flow asymmetry through the bend continues to exist past the bend apex, with the inner bank separation remaining present and the downstream fast flow confined into a thin stream tube between the inner and outer bank apexes. A very slow velocity area at the outer bank bend apex between sections A and B is present, as was also evident for the LFE. In addition, the area of very slow velocity along the inner bank all the way downstream, also simulated for the LFE, 
is still in place. An area of secondary circulation with the classic characteristics of helicoidal flow can be observed in the right-hand half downstream of section $\mathrm{C}$, with bed vectors angled towards the inner bank but surface vectors angled towards the outer bank. The interpretation of secondary circulation is based upon differences between the near bed and the near surface velocity magnitude and direction. The difference in direction is as much as 60 degrees in some places, where the velocity component at the surface can exceed $0.2 \mathrm{~m} / \mathrm{s}$ outwards but that at the bed can exceed $1.2 \mathrm{~m} / \mathrm{s}$ inwards.

Simulated near-bed and near-surface flow patterns corresponding within the downstream part of the large bend area (area of interest 4) are illustrated in Figure 14(c) \& Figure 14(d). Figure 14(c) \& Figure 14(d) and Figure 15(d) demonstrate that the main features of the flow as simulated for the LFE are maintained also at this higher flow discharge. As noted in Figure 15(d), there is an acceleration of the flow towards the bend inner bank apex. Both the near bed $(\sim 1.0 \mathrm{~m} / \mathrm{s})$ and near surface $(\sim 1.5 \mathrm{~m} / \mathrm{s})$ velocities are higher at the inner bank as the flow enters the bend. The outer bank of the bend up to the outer apex is shown to be dominated by low velocities. In addition, the fast flow zone is gradually occupying a larger width of the channel as the flow approaches the inner bank apex.

The dead zone of stagnant flow $(<0.1 \mathrm{~m} / \mathrm{s}$ at both surface and bed) on the left-hand side starting after the peak high velocity downwards of section $\mathrm{B}$ and simulated for the LFE is still in place but is smaller in extent. Although the separation zone on the left side just before section $\mathrm{C}$ remains at this higher stage, it is smaller in extent and the flow structure alters considerably. The large region corresponding to the characteristic helicoidal flow identified for the LFE between sections $\mathrm{B}$ and $\mathrm{C}$ within the relatively fast down channel flow remains in place. Near bed velocity vectors are angled towards the inner (left) bend bank, while surface vectors are angled towards the outer (right) bank. The difference in direction is as much as 45 degrees in some places, where the velocity component at the surface can exceed $1.6 \mathrm{~m} / \mathrm{s}$ to the right, but that at the bed can exceed 1.0 $\mathrm{m} / \mathrm{s}$ to the left.

As can be seen in Figure 16 the overall patterns of simulated bed shear stress for the HFE are not significantly changed in pattern relative to the LFE, but the magnitudes of shear stress are almost twice as high as the flow stage increases. At bank full stage the flow velocities in the separation zones were found to be higher than those simulated for the LFE. The higher magnitudes of velocity and simulated shear stresses through the latter regions will likely result in the removal of accumulated sediments into the main downstream flow. Thus, removal of materials from within the separation zones will act to maintain the presence of the separation zones at low flow stages by permitting erosion of the inner banks. In contrast, the nature and type of outer bank shear stresses (and thus bank erosion) acting in bends or in areas dominated by high velocities for the HFE are found to be similar to those simulated for the LFE. High shear stresses are created at the regions of high velocity in a form of stream tube, especially along 

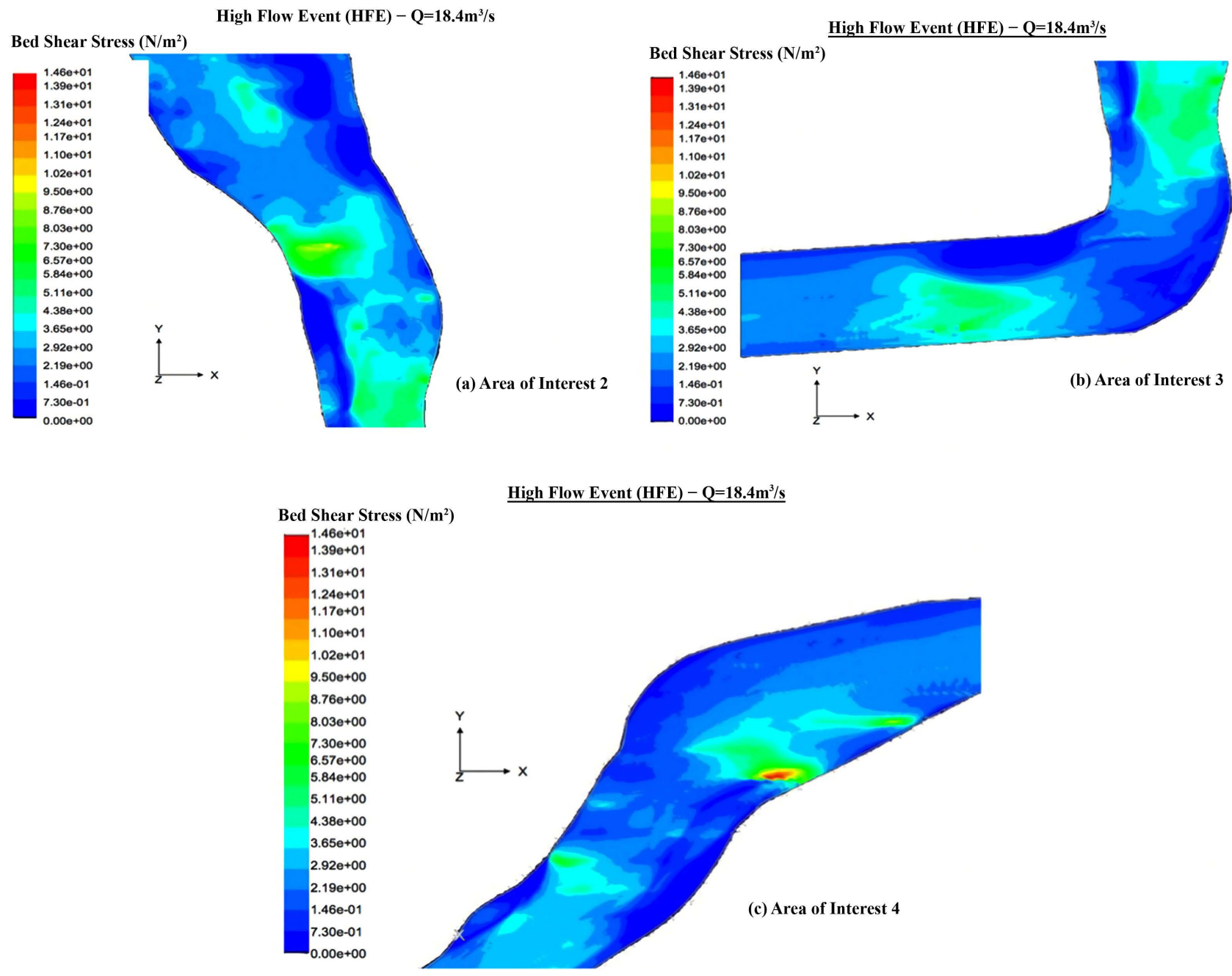

Figure 16. Predicted bed shear stress patterns for Areas of Interest 2 (a), 3 (b), and 4 (c) under high flow conditions $(\mathrm{Q}=18.4$ $\left.\mathrm{m}^{3} / \mathrm{s}\right)$.

the outer banks. As a result, the bank erosion rates are likely to be relatively high in bends with inner bank separation zones.

Present understanding of three-dimensional flow configurations during HFE is established upon limited field investigations that have tended to investigate flow structures only at limited numbers of cross-sections and for a narrow range of flow conditions. For example, Markham and Thorne (1992) examined the influence of flow phase on flow arrangement by carrying out comprehensive velocity observations at three cross sections. It is vital to reference nevertheless that several of these surveys faced difficulties regarding the assembly of the information necessary. More precisely, Markham and Thorne (1992) were only capable of obtaining data at three broadly spaced cross sections over a curvature and had complications in obtaining cross section velocity information at similar flow discharges for both high and low flow phase situations.

The happening and extent of flow separation is based on the manner the hydraulic geometry of the channel is transformed as a consequence of changing 
flow phases (Bridge \& Jarvis, 1982). Nonetheless, the association amongst flow separation incidence and flow phase is still not well agreed particularly in curvatures. The importance of that matter in relation to near bank flows is of prodigious significance as flow separation can be deliberated as a key tool governing the likely commencement of bank erosion.

The results of the three-dimensional time-averaged flow structures presented in these previous studies reveal significant differences in, but some similarities between, the flow structures associated with the various flow events examined herein. Although, the width and depth, as well as the velocities and shear stresses, throughout the River Asker reach increase as flow discharge increases, the main structures of the flow present at the lower discharge are, by and large, retained at the higher flow discharge.

There are several important similarities in the results for the two examined flow events. Both of them have dead zones of slow and areas of recirculating flow located close to the inner banks just downstream of their apices. The presence of recirculation zones acts to confine the main downstream flow into stream tubes of relatively high velocity, these being displaced to a position close to the outer banks. The stream tubes therefore have the effect of increasing flow velocity near the bed and at the toe of the outer bank. In all cases, flow in the stream tubes initially has the classical helical motion with mostly flow directed outwards at the surface but inwards at the bed, with plunging flow at the outer banks. This flow pattern is extremely strong in the first half of the bends, but downstream of their apices it is rapidly dissipated as the near surface and near bed velocities are in a similar direction.

However, there are also notable differences as flow discharge is increased, for example the location of flow impingement of the main flow against the bank tends to occur further downstream as discharge increases. In addition, this impingement is observed downstream of the bends apices, supporting the classical model of flow through bends. The impingement on the outer banks influences the size of flow separation at both banks and is likely to provide a clear control on where erosion and deposition occurs.

Another significant feature within the examined flow events corresponds to inner bank flow separation. Inner bank flow separation is seen to exist even at the higher flow stage, although it is somewhat reduced in both size and extent as discharge increases. This change in flow structure with discharge is similar at both the surface and bed. The flow structure around the separation zones, as well as the movement of the flow into and out of them, is similar for both the flow events investigated.

The size and shape of the recirculation zones and their variations at higher flow stage are likely influenced by the position and size of the deep parts throughout the reach. There is the possibility that the recirculation zones may become stronger when the pools experiences deposition. As a result, velocity and bed/bank shear stress would rise and enable maintenance of the overall reach 
morphology.

Bed/bank shear stress is mostly seen to decrease over shallow riffles as discharge approaches bank full. In contrast, pools experience an increase in bed/bank shear stress with increases in discharge. At the higher discharge, shallow parts of the study reach experience a uniformly distributed decrease in shear stress. This is in contrast with the deeper parts of the channel, where large increases in shear stress are simulated as a function of increasing flow discharge.

Overall, as discharge approaches bank full, the width of the zone of higher near-bed, near-surface velocity, and bed shear stress widens. As discharge rises, marginal dead waters become activated and, in general, decrease in downstream extent, leading to a more fragmented series of low bed shear stress zones. Planform controls on secondary flow clearly affect the migration of the zone of high bed/bank shear stress. As discharge rises, the inner bank zones of low bed/bank shear stress extends upstream and widens downstream whilst it reduces at the outer bank as the high bed/bank shear stress region migrates towards the inner bank.

There is a downstream migration of the zones of faster near-bed and near-surface velocity as well as bed/bank shear stress in pools as the discharge increases. The patterns of boundary shear stress acting on both bed and banks are highly complex. Zones of higher bed/bank shear stress extend and combine, while marginal recirculation zones and areas of relatively low bed/bank shear stress generally reduce in area to form. At bank full stage (HFE), the magnitudes of velocity and simulated shear stresses through the regions of inner bank separation are higher than those simulated in LFE and may be sufficient to result in the removal of accumulated sediments into the main downstream flow. This removal of materials from within the separation zones will act to maintain the presence of the separation zones at low flow stages by permitting erosion of the inner banks.

In contrast, bank erosion seems to be active on the outer banks, increasing in magnitude as flow stage increases. Based on these findings, the nature of the spatial distribution of boundary shear stress in bends, which in turn controls sediment transport and river migration patterns, may differ in some regards from the classical model (e.g., Bridge, 1992). In these classical models, maximum boundary shear stress is located just downstream of the bend apex, on the outer bank, whereas the minimum boundary shear stress is on the inner bank, again just downstream of the bend apex. This leads to a pattern of migration whereby the classical bend increases in amplitude and translates downstream over time. This study confirms the presence of regions of high velocity and shear stress along the outer banks, but the existence of large areas of slow downstream or even reverse flow across the bends within the examined flow events has several important implications. The velocity patterns identified within those bends generally imply maximum boundary shear stress near the outer banks, but with maximum shear stresses located both up and downstream of the bend apex (e.g. 
Figure 16(b)). This suggests that outer bank erosion would be promoted in these zones, with deposition (or less intense erosion) at the apex itself, leading to the progressive evolution of a compounded meander form. The CFD simulations show the importance of resolving flow dynamics within the context of each bend, emphasizing the considerable variability in actual patterns of sediment dynamics, bank erosion and meander migration in natural river meander bends, as compared from the idealized situation depicted by classical models.

\section{Conclusion}

Understanding the controls on river bank erosion is essential for predicting the migration and development of river meanders. Nevertheless, thorough investigations of the erodibility of bank constituents, and of near-bank boundary shear stresses, have been notably lacking from the literature to date. This absence of data makes it challenging to accurately parameterize fluvial erosion models, meaning that there is an urgent need to acquire high-resolution, spatially-distributed, information to describe the near bank fluid shear stresses responsible for driving bank erosion. Since it can be challenging to collect such data using measurement procedures, especially during hazardous high flows, modelling approaches may provide a suitable alternative means of estimating the driving forces responsible for bank erosion.

The foremost objective of this paper was, therefore, to engage CFD methods to attain simulated near-bank boundary shear stress information for diverse channel planform configurations and across a variety of flow conditions. The CFD models were constructed utilizing high-resolution topographic data with upstream boundary conditions quantified by means of flow velocity and water profile information attained during monitoring. In this way, a mixture of field case study observations and CFD modelling was used to examine the time-averaged flow field within the River Asker study reach under a range of flow conditions.

The modelling results show that, for both low and high flow conditions, areas of slow and recirculating flow are located near to the inner banks of the sinuous reach. The occurrence of recirculation regions acts to restrain the downstream flow into stream tubes of comparatively high velocity at places near to the outer banks, especially at higher flow discharges. The stream tubes are characterized by amplified velocity at the toe of the outer bank. In all cases, fast downstream flow with a helical circulation was existent, but the core of high flow velocity is limited to a stream tube of less than half the channel width. The flow within the stream tube is categorized as an extreme helical motion, but both the velocity magnitude and the strength of the helical circulation reduce in locations past the bend apices.

The bed/bank shear stress was typically reduced at shallow riffles as discharge increased towards bankfull. In contrast, pools showed a growth in bed/bank shear stress with increasing discharge. A rise in discharge is also associated with a spreading of the high bed shear stress area. Regions of greater bed/bank shear 
stress spread and combine, whereas recirculation regions and zones of moderately small bed/bank shear stress decrease in extent. At high flow, the extent of velocity and shear stresses over the areas of inner bank separation were found to be greater compared to those simulated at low flow and may be adequate to inhibit the movement of sediment into the main downstream flow. These patterns of modelled flow have consequences for the sediment dynamics, bank erosion and meander migration in the studied reach.

\section{Acknowledgements}

$59 \%$ of this paper comes from "Modelling near-Bank flow hydraulics", my published Thesis, dated June 2009 (University of Southampton, UK). This paper covers the same concept: Usage of Computational Fluid Dynamics (CFD) modelling approach for calculating the rate of bank erosion due to the shear stresses exerted on the river banks during the hazardous high flow events where empirical in-situ identification is difficult to happen. The paper summarizes the findings of the research for the verification and further computational estimation of these near bank shear stresses.

\section{Conflicts of Interest}

The authors declare no conflicts of interest regarding the publication of this paper.

\section{References}

Amoozegar, A. (1989). A Compact Constant-Head Permeameter for Measuring Saturated Hydraulic Conductivity of the Vadose Zone. Soil Science Society of American Journal, 53, 1356-1361. https://doi.org/10.2136/sssaj1989.03615995005300050009x

ASCE Task Committee on Hydraulics, Bank Mechanics and Modeling of River Width Adjustment (1998b). River Width Adjustment. II: Modeling. Journal of Hydraulic Engineering, 124, 903-917. https://doi.org/10.1061/(ASCE)0733-9429(1998)124:9(903)

Ashmore, P. E., Ferguson, R. I., Prestegaard, K. L., Ashworth, P. J., \& Paola, C. (1992). Secondary Flow in Anabranch Confluences of a Braided, Gravel-Bed Stream. Earth Surface Processes and Landforms, 17, 299-311. https://doi.org/10.1002/esp.3290170308

Bridge, J. S., \& Jarvis, J. (1982). The Dynamics of a River Bend: A Study in Flow and Sedimentary Processes. Sedimentology, 29, 499-541. https://doi.org/10.1111/j.1365-3091.1982.tb01732.x

Bridge, J. S. (1992). A Revised Model for Water Flow, Sediment Transport, Bed Topography and Grain Size Sorting in Natural River Bends. Water Resources Research, 28, 999-1013. https://doi.org/10.1029/91WR03088

Casagli, N., Rinaldi, M., Gargini, A., \& Curini, A. (1999). Pore Water Pressure and Streambank Stability: Results from a Monitoring Site on the Sieve River, Italy. Earth Surface Processes and Landforms, 24, 1095-1114. https://doi.org/10.1002/(SICI)1096-9837(199911)24:12<1095::AID-ESP37>3.0.CO;2-F

Dapporto, S. (2001). Non-Vertical Jet Testing of Cohesive Streambank Toe Material. Oxford: School of Geography, University of Nottingham, in Collaboration with USDA-ARS National Sedimentation Laboratory. 
Darby, S. E., Trieu, H. Q., Carling, P. A., Sarkkula, J., Koponen, J., Kummu, M., \& Leyland, J. (2010). A Physically Based Model to Predict Hydraulic Erosion of Fine-Grained Riverbanks: The Role of Form Roughness in Limiting Erosion. Journal of Geophysical Research, 115, F04003. https://doi.org/10.1029/2010JF001708

Darby, S. E., Leyland, J., Kummu, M., Rasanen, T., \& Lauri, H. (2013). Decoding the Drivers of Bank Erosion on the Mekong River: The Roles of the Asian Monsoon, Tropical Storms and Snow Melt. Water Resources Research, 49, 2146-2163. https://doi.org/10.1002/wrcr.20205

Dietrich, W. E. (1987). Mechanics of Flow and Sediment Transport in River Bends. In K. S. Richards (Ed.), River Channels: Environment and Process (pp. 179-227). Oxford: Blackwell.

Dietrich, W. E., \& Smith, J. D. (1984). Bed-Load Transport in a River Meander. Water Recourses Research, 20, 1355-1380. https://doi.org/10.1029/WR020i010p01355

Fluent Inc. (2006). Fluent 6.2 User's Guide. Lebanon: Fluent Incorporated, NH 03766.

Leyland, J., Darby, S. E., Teruggi, L., Rinaldi, M., \& Ostuni, D. (2015). A Self-Limiting Bank Erosion Mechanism? Inferring Temporal Variations in Bank Form and Skin Drag from High Resolution Topographic Data. Earth Surface Processes and Landforms, 40, 1600-1615. https://doi.org/10.1002/esp.3739

Hackney, C., Best, J., Leyland, J., Darby, S. E., Parsons, D., Aalto, R., \& Nicholas, A. (2015). Modulation of Outer Bank Erosion by Slump Blocks: Disentangling the Protective and Destructive Role of Failed Material on the Three-Dimensional Flow Structures. Geophysical Research Letters, 42, 10663-10670.

https://doi.org/10.1002/2015GL066481

Hackney, C., Darby, S.E, Parsons, D., Leyland, J., Best, J., Aalto, R., \& Houseago, R. (2020). River Bank Instability from Unsustainable Sand Mining in the Lower Mekong River. Nature Sustainability, 3, 217-225. https://doi.org/10.1038/s41893-019-0455-3

Hanson, G. J., \& Simon, A. (2001). Erodibility of Cohesive Streambeds in the Loess Area of the Midwestern USA. Hydrological Processes, 15, 23-38. https://doi.org/10.1002/hyp.149

Kean, J. W., \& Smith, J. D. (2006). Form Drag in Rivers Due to Small-Scale Natural Topographic Features: 1. Regular Sequences. Journal of Geophysical Research, 111, F04009. https://doi.org/10.1029/2006JF000467

Lane, S. N., Bradbrook, K. F., Richards, K. S., Biron, P. A., \& Roy, A. G. (1999b). Time-Averaged Flow Structure in the Central Region of a Stream Confluence: A Discussion. Earth Surface Processes and Landforms, 24, 361-367. https://doi.org/10.1002/(SICI)1096-9837(199904)24:4<361::AID-ESP982>3.0.CO;2-5

Lawler, D. M., Thorne, C. R., \& Hooke, J. M. (1997). Bank Erosion and Instability. In C. R. Thorne, R. D. Hey, \& M. D. Newson (Eds.), Applied Fluvial Geomorphology for River Engineering and Management (pp. 137-172). Chichester: John Wiley.

Lutenegger, A. J., \& Hallberg, G. R. (1981). Borehole Shear Test in Geotechnical Investigation. In R. Yong, \& F. Townsend (Eds.), Laboratory Shear Strength of Soil (pp. 566-578). Special Technical Publ. 740, West Conshohocken, PA: ASTM International. https://doi.org/10.1520/STP28771S

Markham, A. J., \& Thorne, C. R. (1992). Geomorphology of Gravel-Bed River Bends. In P. Billi, R. D. Hey, C. R. Thorne, \& P. Tacconi (Eds.), Dynamics of Gravel-Bed Rivers (pp. 433-450). Chichester: Wiley.

Midgley, T. L., Fox, G. A., \& Heeren, D. M. (2012). Evaluation of the Bank Stability and Toe Erosion Model (BSTEM) for Predicting Lateral Retreat on Composite Streambanks. Geomorphology, 145-146, 107-114. 
https://doi.org/10.1016/j.geomorph.2011.12.044

Osman, A. M., \& Thorne, C. R. (1988). Riverbank Stability Analysis. I: Theory. Journal of Hydraulic Engineering, 114, 134-150.

https://doi.org/10.1061/(ASCE)0733-9429(1988)114:2(134)

Partheniades, E. (1965). Erosion and Deposition of Cohesive Soils. Journal of the Hydraulics Division, Proceedings of the American society of Civil Engineers, 91, 105-139.

Rhoads, B. L., \& Sukhodolov, A. (2001). Field Investigation of Three-Dimensional Flow Structure at Stream Confluences: 1. Thermal Mixing and Time-Averaged Velocities. Water Resources Research, 37, 2393-2410. https://doi.org/10.1029/2001WR000316

Rinaldi, M., \& Casagli, N. (1999). Stability of Streambanks Formed in Partially Saturated Soils and Effects of Negative Pore Water Pressures: The Sieve River, Italy. Geomorphology, 26, 253-277. https://doi.org/10.1016/S0169-555X(98)00069-5

Sharc Ltd. (2006). Harpoon Used Guide. http://www.sharc.co.uk

Simon, A., \& Collison, A. J. C. (2002). Quantifying the Mechanical and Hydrologic Effects of Riparian Vegetation on Streambank Stability. Earth Surface Processes and Landforms, 27, 527-546. https://doi.org/10.1002/esp.325 